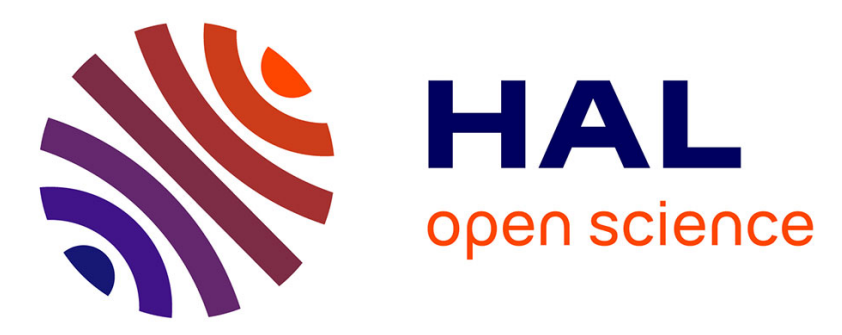

\title{
In search of autobiographical memories: A PET study in the frontal variant of frontotemporal dementia.
} Pascale Piolino, Gaël Chételat, Vanessa Matuszewski, Brigitte Landeau, Florence Mézenge, Fausto Viader, Vincent de La Sayette, Francis Eustache, Béatrice Desgranges

\section{To cite this version:}

Pascale Piolino, Gaël Chételat, Vanessa Matuszewski, Brigitte Landeau, Florence Mézenge, et al.. In search of autobiographical memories: A PET study in the frontal variant of frontotemporal dementia.: Neural correlates of AM in fv-FTD. Neuropsychologia, 2007, 45 (12), pp.2730-43. 10.1016/j.neuropsychologia.2007.04.013 . inserm-00142874

\section{HAL Id: inserm-00142874 https://www.hal.inserm.fr/inserm-00142874}

Submitted on 30 May 2007

HAL is a multi-disciplinary open access archive for the deposit and dissemination of scientific research documents, whether they are published or not. The documents may come from teaching and research institutions in France or abroad, or from public or private research centers.
L'archive ouverte pluridisciplinaire HAL, est destinée au dépôt et à la diffusion de documents scientifiques de niveau recherche, publiés ou non, émanant des établissements d'enseignement et de recherche français ou étrangers, des laboratoires publics ou privés. 


\section{Accepted Manuscript}

Title: In search of autobiographical memories: A PET study in the frontal variant of frontotemporal dementia

Authors: Pascale Piolino, Gaël Chételat, Vanessa Matuszewski, Brigitte Landeau, Florence Mézenge, Fausto

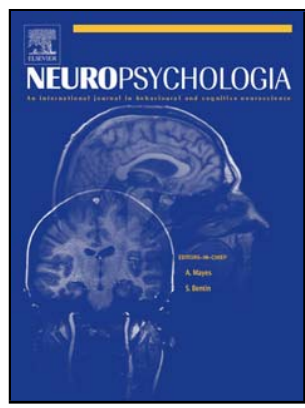
Viader, Vincent de la Sayette, Francis Eustache, Béatrice Desgranges

PII: S0028-3932(07)00154-6

DOI: doi:10.1016/j.neuropsychologia.2007.04.013

Reference: NSY 2605

To appear in: Neuropsychologia

Received date:

Revised date:

Accepted date: 6-4-2007

Please cite this article as: Piolino, P., Chételat, G., Matuszewski, V., Landeau, B., Mézenge, F., Viader, F., de la Sayette, V., Eustache, F., Desgranges, B., In search of autobiographical memories: A PET study in the frontal variant of frontotemporal dementia, Neuropsychologia (2007), doi:10.1016/j.neuropsychologia.2007.04.013

This is a PDF file of an unedited manuscript that has been accepted for publication. As a service to our customers we are providing this early version of the manuscript. The manuscript will undergo copyediting, typesetting, and review of the resulting proof before it is published in its final form. Please note that during the production process errors may be discovered which could affect the content, and all legal disclaimers that apply to the journal pertain. 
In search of autobiographical memories: a PET study in the frontal variant of frontotemporal dementia

Pascale Piolino ${ }^{1,2}$, Gaël Chételat ${ }^{1}$, Vanessa Matuszewski ${ }^{1}$, Brigitte Landeau ${ }^{1}$, Florence Mézenge $^{1}$, Fausto Viader ${ }^{1,3}$, Vincent de la Sayette ${ }^{1,3}$, Francis Eustache ${ }^{1}$, Béatrice Desgranges $^{1^{*}}$

${ }^{1}$ Inserm-EPHE-Université de Caen Basse-Normandie, Unité E0218, Caen, France

${ }^{2}$ CNRS-Université René Descartes Paris 5, FRE 2987-Laboratoire de Psychologie et Neurosciences Cognitives, Paris, France

${ }^{3}$ CHU Côte de Nacre, Département de Neurologie, Caen, France

\section{Running title: Neural correlates of AM in fv-FTD}

Abbreviations: AM: autobiographical memory; fv-FTD: frontal variant of frontotemporal dementia; FDG = fluorodeoxyglucose; FOV: field of view; SPM: Statistical Parametric Mapping; PET: Positron Emission Tomography; PVE: partial volume effect; BA: Brodmann's area.

Corresponding author. Dr Béatrice Desgranges, Inserm-EPHE-Université de Caen BasseNormandie, Unité E 0218, CHU Côte de Nacre, 14033 Caen Cedex, France.

E-mail: desgranges-b@,chu-caen.fr

Fax $+33(0) 231065198$ 


\section{Abstract}

Patients suffering from frontal variant of frontotemporal dementia (fv-FTD) undergo autobiographical amnesia encompassing all time periods. We previously demonstrated in a group of $20 \mathrm{fv}-\mathrm{FTD}$ patients, that this impairment involved deficits in executive function and semantic memory for all periods as well as new episodic learning and behavioural changes for the most recent period covering the last 12 months (Matuszewski et al., 2006). The aim of the present study was to unravel the neural bases of this impairment by mapping in a subgroup of patients the correlations between resting-state brain glucose utilization measured by FDGPET and measures of autobiographical memory (AM) using the TEMPau task which is designed to gauge personal event recollection across five life time periods. Like in our previous report, the group of patients was impaired regardless of time periods compared to healthy subjects providing generic memories instead of event specific sensory-perceptualaffective details, i.e. episodic memories. New data showed that the patients were also impaired in sense of reliving and self-perspective during retrieval. The cognitivo-metabolic correlations between the AM score and resting normalized FDG-Uptake were computed using statistical parametric mapping (SPM2) and controlling for age and dementia severity. They revealed that AM deficits were mainly subserved by the dysfunction of left-sided orbitofrontal and also temporal neocortical areas whatever the period. Additional analysis showed that specific memories were associated with left orbitofrontal areas whereas generic memories were mainly associated with the left temporal pole. This study supports the view that fv-FTD patients undergo a breakdown of generative processes which relies regardless of the remoteness on the left orb itofrontal cortex and temporal neocortex to gain access to AM.

Keywords: Frontotemporal dementia; orbitofrontal cortex; autobiographical memory; retrieval; autonoetic consciousness, self-perspective, PET 


\section{Introduction}

Frontal variant of frontotemporal dementia (fv-FTD) is the most common form of degenerative dementia after Alzheimer's disease, accounting for $20 \%$ of cases of dementia occurring in presenium (Snowden, Neary \& Mann, 2002). Patients suffering from fv-FTD show marked changes in behaviour and personality and impaired in sights (e.g. disinhibition, diminished motivation, apathy and distractibility, Miller et al., 2001; Mychack, Kramer, Boone \& Miller, 2001; Williams, Nestor \& Hodges, 2005). They exhibit executive deficits related to predominant frontal lobe atrophy. At the early stage of the disease, day to day memory is relatively preserved (Kramer et al., 2003; Neary et al., 1998; Perry \& Hodges, 2000), although some patients may have deficits in episodic memory tasks (Hodges \& Miller, 2001). Moreover, they have a substantial autobiographical amnesia regardless of the age of memories encompassing both retrograde and anterograde periods (Hodges \& Gurd, 1994; Nestor, Graham, Bozeat, Simons \& Hodges, 2002; Matuszewski et al., 2006; Piolino et al., 2003; Thomas-Antérion, Jacquin \& Laurent, 2000; Hou, Miller \& Kramer, 2005). Some studies suggest that the mechanisms at the root of autobiographical memory (AM) impairment may reflect a deficit of strategic processes sustained by executive/frontal dysfunction (Matuszewski et al., 2006; Nestor et al., 2002; Piolino et al., 2003) since the memory deficits in fv-FTD have been attributed to "attentional deficits or inefficient retrieval due to frontal lobe dysfunction" (Rosen et al., 2004). Nowadays, the issue of impaired mechanisms is confused for two main reasons, - one related to the multifaceted nature of AM, - the other related to the relative widespread cerebral dysfunction in fv-FDT.

AM consists of a set of information as well as memories specific to an individual, which have been accumulated since early in life and allow him or her to construct a feeling of identity and continuity. AM and the self are closely linked, as the former grounds the latter and vice versa (Wilson \& Ross, 2003). Conway and colleagues (Conway \& Pleydell-Pearce, 
2000; Conway, Singer \& Tagini, 2004; Conway, 2005) introduced the Self Memory System (SMS) as a model of the relationship of AM to the self. The self, which includes current goals and motivations, determines the construction of autobiographical memories during encoding and retrieval processes. The SMS model postulates that autobiographical memories are transitory mental constructions of a complex self goal-driven set of control processes (i.e. the working self) which interact with the long-term self semantic knowledge and the episodic memory system. The latter contains specific "sensory-perceptual-cognitive-affective details" events that elicit visual imagery and autonoetic experience (Tulving, 1985) of mentally "reliving" a past event. According to this constructive framework, the recollection of episodic autobiographical memories that ensures a sense of remembering requires a complex cyclic retrieval process depending on the prefrontal cortex, which allows access to event-specific knowledge (e.g., images, feelings) from personal semantic knowledge base. Therefore, breakdown in executive function, but also in episodic and semantic memory, can play a role in AM disruption. Recently, we demonstrated in a group of $20 \mathrm{fv}-\mathrm{FTD}$ (Matuszewski et al., 2006) that AM deficits were mainly linked to disruption of executive function and semantic memory regardless the age of memories. As regards the most recent memories, they were also related to a lesser degree to episodic memory deficits and behavioural changes. As these findings were based on a correlational analysis between cognitive measures, further researches should be helpful to unravel the neural basis of this impairment and to confirm the main role of executive/frontal dysfunction on AM deficits in fv-FTD.

From a cerebral viewpoint, neuropsychological studies have shown that AM is disrupted by right-sided or bilateral fronto-temporal lobe lesions (see Markowitsch, 1995; Conway \& Fthenaki, 2000; Kopelman \& Kapur, 2001 for reviews) and more posterior lesions (Rubin \& Greenberg, 1998). Kopelman and his colleagues (2003) have shown that the frontal brain volume predicted $60-68 \%$ of AM performances (for incidents and facts) in patients with 
frontal lesions. Functional neuroimaging studies have highlighted the role of a large neocortical network, including the prefrontal cortex in the initiation of autobiographical reconstructive processes (Conway, Pleydell-Pearce \& Whitecross, 2001). Overall, the general activation pattern across studies during AM retrieval involves an extensive preferentially leftsided cerebral network comprising prefrontal cortex, medial temporal, temporoparietal junction, posterior cingulate/retrosplenial cortex, precuneus, occipital and cerebellar regions, as stressed by several authors (e.g. Conway, Pleydell-Pearce, Whitecross \& Sharpe, 2002; Maguire, 2001; Piolino et al., 2004). This left-sided involvement contrasts with findings of lesions studies which emphasize the role of right areas instead. Nevertheless, some studies emphasized the involvement of right or bilateral regions, especially the hippocampus, depending on the episodic quality of memories (e.g., Graham, Lee, Brett \& Patterson, 2003; Gilboa, Winocur, Grady, Hevenor \& Moscovitch, 2004; Piolino et al., 2004; Steinvorth, Corkin \& Halgren, 2006; Viard et al., 2007) or on the old age of the subjects (Maguire \& Frith, 2003). These data suggested that episodic autobiographical memories are triggered off in prefrontal cortex and generated through information stored in networks situated towards the posterior of the brain. Therefore, AM should be disrupted by damage to specific cerebral structures or by their disconnection.

Beside, both structural and functional neuroimaging studies in fv-FTD have shown that the locus of pathology in fv-FTD typically starts in ventromedial portions of the prefrontal cortex (Hodges et al., 1999; Lough, Gregory \& Hodges, 2001; Salmon et al., 2003; Schroeter, Raczka, Neumann \& von Cramon, 2006), which are involved in disinhibition and impulsivity (Hodges et al., 1999; Hodges \& Miller, 2001; Snowden et al. 2001; but see Williams et al., 2005), changes in social conduct, personality, self, general loss of emotional responsiveness and interpersonal skills (Brazzelli, Colombo, Della Sala \& Spinnler, 1994; Gregory et al., 2002; Miller, Seeley, Mychack, Rosen, Mena \& Boone, 2001), and then 
extends to dorsolateral prefrontal cortex, which underlies planning and other higher cognitive functions (Sarazin, Pillon, Giannakopoulos, Rancurel, Samson \& Dubois, 1998). These studies have also high lighted widespread alterations which are not limited to the frontal lobe but concern other cortical and subcortical structures (see Tomaszewski \& Jagust, 2004, for review) which are involved in AM. Thus, the neural basis for AM breakdown in fv-FTD more especially regarding the different regions of the prefrontal cortex remains an open question.

The aim of the present study was therefore to unravel the cerebral structures subserving autobiographical memory deficits in a subgroup of fv-FTD patients where we previously showed that this impairment involved deficits in executive function and semantic memory for all periods as well as new episodic learning and behavioural changes for the most recent period covering the last 12 months (Matuszewski et al., 2006). Voxel-based mapping of the correlations between memory performance and resting regional metabolic rates of glucose measured by positron emission tomography (PET) has been demonstrated to be a sensitive approach to delineate the neural substrates of cognitive impairment in patients with frontal lobe lesions (Reed, Lasseron, Marsden, Bright, Stanhope \& Kopelman, 2005), and in degenerative diseases such as Alzheimer's disease (see for example, Perani, Bressi, Cappa, Vallar, Alberoni, Grassi et al., 1993; Desgranges, Baron, Lalevée, Giffard, Viader, de la Sayette et al., 2002; Desgranges, Baron, Giffard, Chételat, Lalevée, Viader et al., 2002; Eustache, Desgranges, Giffard, de la Sayette \& Baron, 2001; Rauchs, Piolino, Mézenge, Landeau, Lalevée, Pélerin, et al., 2006), more precisely to enlighten the neural basis of AM deficits in Alzheimer's disease (Eustache et al., 2004). In the present study, we used PET and statistical parametric mapping (SPM) to map the correlations between resting-state FDGUptake in the whole brain and scores reflecting AM in a group of fv-FTD patients. 


\section{Materials and methods}

\section{Subjects}

The thirteen unmedicated fv-FTD patients $(\mathrm{MMS}=24.8 \pm 4$; age $=67.2 \pm 7.9)$ included in the study came from a group of twenty patients presented elsewhere in details (Matuszewski et al., 2006) who had undergone a general cognitive assessment and AM study. In addition, within an interval of few days, the present patients underwent a PET measurement of resting $\left[{ }^{18} \mathrm{~F}\right]$ fluoro-2-deoxy-D-glucose $\left({ }^{18} \mathrm{FDG}\right)$ and a high-resolution T1weighted volume MRI scan, used to process the PET data. For the other patients neuroimaging data were missing or defective (e.g. because of moves during scanning). Every subject gave informed consent to the neuropsychological and imaging procedure, which was approved by the local Ethical Committee.

The patients were selected according to the consensus diagnostic criteria of Neary et al. (1998) and they were diagnosed within the last 2 years at the most. For each patient, the selection was made, according to strict criteria, by the medical and neuropsychological staff. They all presented with early impairment in social interpersonal conduct and in regulation of personal conduct, early emotional blunting and loss of insight as based on historical information provided by the patients' family and on a French version of the "Dysexecutive questionnaire" (DEX) from the Behavioural Assessment of Dysexecutive Syndrome battery (BADS, Wilson, Alderman, Burgess, Emslie \& Evans, 1996) fulfilled by the patients which assesses the presence of emotional or personality changes, motivational, behavioural, and cognitive changes. We did not exclude patients with episodic or semantic disorders provided that these deficits were not severe in daily life activities (i.e. preserved day-to-day memory) and, above all, had not preceded the behavioural and executive disorders as attested by family members and/or the clinical staff. Patients with a history of alcoholism, significant head 
injury, neurological or psychiatric illness, or progressive non-fluent aphasia were excluded. Moreover for the purpose of this study, which focused the interest on "true" memories, not false ones (Burt, Kemp \& Conway, 2004), we selected fv-FTD patients who did not show major sign of confabulation based on clinical examination and performances in the episodic and semantic "don't know schedule" of the Confabulatory Memory Battery of Dalla Barba (1993).

The patients underwent a general cognitive assessment (see Matuszewski et al., 2006 for details of the assessment and results in the whole group of 20 patients). They were compared with 21 control subjects (age: mean $=69.85 \pm 8.57$ years; range $51-80$ years; $\geq 8$ years of education) paired according to age and level of education. To assess the executive function, following the conception of Miyake, Friedman, Emerson, Witzki, and Howerter (2000), we investigated the shifting process, inhibition of inappropriate responses and updating function using the trail making test (Reitan, 1958), the Stroop test (Stroop, 1935) and the running span task (Quinette, Guillery, Desgranges, de la Sayette, Viader \& Eustache, 2003), respectively. We also used categorical (names of animals) and letter (words beginning with the letter 'p') verbal fluency tasks (Cardebat, Doyon, Puel, Goulet \& Joanette, 1990). Although these tasks involve other cognitive processes (e.g. semantic memory), they mainly rely on the ability to initiate systematic search and retrieval strategies (Tröster, Warmflash, Osorio, Paolo, Alexander, Barr et al., 1995). According to Baddeley's model (Baddeley, 1986) of working memory, we used a dual-task paradigm (Baddeley, 1997) and backward digit and visuospatial spans to assess the central executive. As regards the slave systems, we assessed the phonological loop and visuospatial sketchpad by using forward digit and visuospatial spans (Wechsler, 1969). In order to evaluate verbal episodic memory, we assessed immediate, total recall and delayed recall of a modified version of the Grober and 
Buschke test (Grober and Buschke, 1987), which adds a procedure to check the semantic integrity of the words to be learned (Eustache et al., 2001). Finally, we explored semantic memory by means of 1) an oral naming task (DO 80, Deloche \& Hannequin, 1997), 2) a semantic knowledge task assessing naming of drawings, categorical and attribute knowledge of concepts (SKT, Giffard, Desgranges, Nore-Mary, Lalevée, de la Sayette, Pasquier et al., 2001), and 3) a personal semantic (names of personal acquaintances) verbal fluency tasks (Piolino, Belliard, Desgranges, Perron \& Eustache, 2003).

The performances of the 13 patients (Table 1) showed severe impairment of executive function, more specially shifting, inhibition, updating, strategic processes, as attested by their performances obtained at the Trail Making test, the Stroop test, the running span and categorical and phonetic fluency tasks,, respectively. The central executive of Baddeley's model of working memory was preserved in our patient group. As regards the slave systems, the patients showed preserved performances for the visuospatial sketchpad but deficits for the phonological loop. Moreover, verbal episodic memory deficits were present as well as semantic memory deficits regardless of the task.

Moreover, we looked at the intercorrelation coefficients between the executive performances and the other general cognitive performances in order to find out if a general executive breakdown could explain all the deficits observed. Overall, the results showed significant relationships (Spearman test, $\mathrm{p}<.05$ ) between performances on executive tests (TMT B, Stroop), central executive of working memory (backward spans) and DEX. There was also a significant link between performances on central executive function (backward digit span) and episodic memory test (delayed recall), but semantic memory performances were not correlated with executive functions.

Briefly, the results of the general cognitive assessment revealed a dramatic executive dysfunction, but also phonological loop, new episodic learning (either encoding, storage or 
retrieval processes) and semantic memory deficits. The findings were similar to those reported in our previous publication on a larger sample of fv-FTD patients (Matuszewski et al., 2006). As regards semantic memory deficits, our findings correspond to other studies in fv-FTD which also reported that the deficits in executive functions may be coupled with semantic breakdown (Hodges \& Miller, 2001). Moreover, our patients were somewhat older than those described in the literature (Ratnavalli, Brayne, Dawson \& Hodges, 2002; Snowden et al., 2002; Hou et al., 2005), which may also have amplified the deficits observed at least in some tasks. Finally, the preservation of central executive of working memory as opposed to executive dysfunction is not unprecedented in fv-FTD (Perry \& Hodges, 2000).

\section{Autobiographical memory assessment}

The TEMPau task is a semi-structured questionnaire (Piolino et al., 2003, Piolino et al., 2006) which assesses the ability to recall detailed specific events situated in time and space from five time periods (0-17 years old, 18-30 years old, over 30 years old, 5 last years and the 12 last months). Patients were given precise instructions to recall a personal event which occurred only once, at a particular place and date, and lasted several minutes or hours but less than a day, with as many details as they could. Given that the patients were diagnosed with in the last 2 years at the most, the three most remote periods (0-17 years old, 18-30 years old, over 30 years old) assessed retrograde memory processes (i.e. retrieval or storage of information acquired before the beginning of the disease) whereas the most recent period (the 12 last months) mainly measured anterograde memory processes (i.e. encoding, storage and retrieval of information acquired after the beginning of the disease). The 5 last years period was considered as mixed involving both retrograde and anterograde memory processes. Each time period assessed the recall of 4 memories from 4 different topics (e.g. "an event linked to a person-the last 5 years"). For the most recent lifetime period, 8 memories were asked from 
questions allowing a chronological study of the recent past from hours before testing to last summer. In cases of difficulty to retrieve a personal event, systematic general clues were provided related to a period (e.g., "when taking a written or oral exam such as school leaving certificate") as well as encouragements to be specific when the memory was generic (e.g., "Do you remember a particular day?") without time constraint. Thereafter, each memory was checked by a re-test $15 \pm 2$ days after the task which consisted of asking the subject to recall in a random order the content and the spatio-temporal situation of each memory, and by a member of the family when possible.

Each event was scored on a 4-point scale which took into account the specificity of the content (single or repeated event), spatio-temporal situation, and the presence of sensoryperceptual-affective details. For example, a specific event situated in time and in space with the presence of internal details (i.e., perceptions, thoughts, feelings) - that was strictly episodic memory - was scored 4 points. A specific event without any details but situated in time and space was scored 3. A repeated or extended event was scored 2 if it was situated in time and space or 1 if it was not. An absence of memory, or only general information about a theme, was scored 0.

Two scores were recorded per period : the autobiographical score (AM score) which summed up the point obtained for each memory and the strictly episodic autobiographical score (EM score) which just summed up the point obtained for specific detailed events (i.e. scored 4 points). Moreover, in order to better delineate the pattern of performances of patients, we recorded the proportion of each kind of memory per period (number divided by the number of memories recalled for each period): i.e., ratio of generic memories (scored 1 and 2), specific memories (scored 3), and of specific and detailed memories (scored 4). The scores were recorded according to the information supplied in the test and corroborated in the 
retest and by a member of the family. Two independent raters (VM and PP) rated each memory and the cases of disagreement are examined until a consensus is formed.

Otherwise, qualitative characteristics of each memory were recorded by asking the patients to report their self-perspective and self-consciousness during retrieval (for details see Piolino et al., 2006). Indeed, the way people recall matters as much as the content of their memories (Conway \& Pleydell-Pearce, 2000; Wilson \& Ross, 2003). The essence of episodic aspects of AM lies on the phenomenal experience of remembering (Brewer, 1996; Tulving, 2001; Wheeler, Stuss \& Tulving, 1997) which almost invariably involves some sort of visual reexperiencing of a personal event (Brewer, 1996; Conway, 2001; Conway, 2005).

First, the patients estimated their self-perspective accompanying mental imagery related to each memory via the field/observer paradigm (Nigro \& Neisser, 1983). They were required to give either observer response if they saw themselves in the scene as a spectator or a field response if they saw the scene through their own eyes, as if they were reliving the event from something like the original perspective as an actor would. Finally, they could also give a mixed field/observer response if they switched from one perspective to another.

Second, the patients reported their state of consciousness accompanying the retrieval via the remember/know paradigm (Tulving, 1985; Gardiner, 1988), allowing to distinguish sense of remembering and sense of just knowing with separate assessment for the factual, spatial, and the temporal contents of each memory. They were required to give a remember response when they recollected subjective experiences from the encoding context. Additionally, the participants were asked to provide sensory and/or affective details or spatiotemporal details that justified each remember response.

For both paradigms, we recorded the proportion of each kind of response (number divided by the number of memories recalled for each period) per period: i.e., the ratio of field, 
observer and field/observer perspectives and the ratio of remember and justified remember responses.

The task was proposed to the group of fv-FTD patients as well as to a control group of 25 normal subjects matched for age (mean $=64.84 \pm 3.27$, range 61-71) and education level. Statistical analysis of the data recorded for the TEMPau task was processed with an analysis of variance (ANOVA) to examine the influence of the group (between factor fv-FTD vs. controls) and period (within factor). We also examined in the fv-FTD group the correlations between generic and specific memories, on the one hand, and the general cognitive assessment and behavioural changes on the other hand.

\section{PET methodology}

All the patients underwent a $\mathrm{T}_{1}$-weighted volume MRI scan acquired on the same scanner (1.5 T Signa Advantage echospeed; General Electric) and a resting PET study using $\left[{ }^{18}\right.$ F]Fluoro-2-deoxy-D-glucose. Data were collected using the high-resolution PET device ECAT Exact HR+ with isotropic resolution of $4.6 \times 4.2 \times 4.2 \mathrm{~mm}(\mathrm{FOV}=158 \mathrm{~mm})$. $\left[{ }^{18}\right.$ F $]$ Fluoro-2-deoxy-D-glucose uptake was measured in the resting condition, with eyes closed, in a quiet and dark environment. A catheter was introduced in a vein of the arm for radiotracer administration. Following ${ }^{68} \mathrm{Ga}$ transmission scans, 3-5 $\mathrm{mCi}$ of $\left[{ }^{18} \mathrm{~F}\right]$ Fuoro-2deoxy-D-glucose were injected as a bolus at time 0 , and a 10 min PET data acquisition period was begun at 50 min post-injection. Sixty-three planes were acquired with septa out (volume acquisition), using a voxel size of $2.2 \times 2.2 \times 2.43 \mathrm{~mm}(\mathrm{x}, \mathrm{y}, \mathrm{z})$. During PET data acquisition, head motion was monitored continuously with laser beams.

Actual glucose metabolic values in fv-FTD patients measured using PET may be underestimated because of brain atrophy, which accentuates the partial volume effect (PVE) on data collected. In order to avoid this bias, the PET data were corrected for PVE due to both cerebro-spinal fluid and white matter using the optimal voxel-by-voxel method originally 
divised by Müller-Gartner et al. (1992) with slight modifications proposed by Rousset, Ma and Evans (1998), described in details in Quarantelli et al. (2004), and already used in our laboratory (Chételat et al., 2003). Unlike the classic Müller-Gartner method, which extracts the white mater tracer uptake value from a large white mater region, the modified method performs a more accurate estimation of this white mater value, based on the ROI method. This method takes into account not only the loss of grey matter activity as a result of spill-out onto extraparenchymal tissues, but also the gain in grey matter as a result of spill-in from adjacent white mater. All image processing steps were carried out using the 'PVE-lab' software. Using statistical parametric mapping (SPM2; Wellcome Dept of Cognitive Neurology, London, UK), the PVE-corrected PET data were then subjected to coregistration onto their respective MRI, spatial normalization using parameters obtained from the normalization of the corresponding MRI data into a customized MRI template obtained from our patient sample, and to a reslicing of $2 \times 2 \times 2 \mathrm{~mm}$. The spatially normalized sets were then smoothed with a $14 \mathrm{~mm}$ isotropic Gaussian filter to blur individual variations in gyral anatomy and to increase the signal-to-noise ratio. The "proportional scaling" routine was applied to the PVE-corrected PET data to control for individual variations in global FDGUptake. In order to minimize "edge effects" without excluding hypometabolic tissue in our fv-FTD subjects, only those voxels with values $>40 \%$ of the mean for the whole brain were selected for the statistical analysis.

The correlations between the AM measures and resting ${ }^{18} \mathrm{FDG}$ uptake in the whole brain were performed using SPM2. Given that there was an insufficient spread in the distribution of EM scores in the patients group (see below), we just carried out the correlations for the AM score according to the time periods. Nevertheless, in order to better disentangle different processes underlying AM retrieval, we also carried out correlations between resting ${ }^{18} \mathrm{FDG}$ uptake and the percentage of specific memories (scored 3 and 4) or 
generic memories (scored 1 and 2), combining all time periods. Finally, in order to gauge the issue of the specificity of results concerning AM, we performed SPM correlations between resting ${ }^{18} \mathrm{FDG}$ uptake and the general cognitive measures. For all these correlations, the influence of age and the overall dementia severity were controlled by setting age and MMSE (Folstein, Folstein \& McHugh, 1975) as confounding variables in a single linear regression. Only the correlations in the neurobiologically expected direction were conducted, i.e. positive correlation for correct responses (e.g., the percentage of specific memories) and negative correlation for errors (e.g., the percentage of generic memories). We used a statistical threshold of $\mathrm{p}<0.005$ (uncorrected for multiple tests) for the voxels and a cut-off of $\mathrm{k}$ (corresponding to the number of voxels in a particular cluster) $>100$, to limit the attending risk of false-positives. Anatomical localization was according to Talairach's Atlas, using M. Brett's set of linear transformations (see http://www.mrccbu.cam.ac.uk/Imaging/mnispace.html) and aal Toolbox (Tzourio-Mazoyer et al., 2002).

\section{Results}

\section{Autobiographical me mory data}

Figure 1 presents the results for the TEMPau task regarding the $A M$ and $E M$ scores. An ANOVA (group $\mathrm{x}$ period) conducted for both scores showed a significant main effect of group $(F(1,36)=68.25$ and $62.65, \mathrm{p}<.0001)$. The period effect was significant only for the AM score $(\mathrm{F}(4,144)=6.97, \mathrm{p}<.0001)$ indicating that the performances of the last 5 years period were lower than the other periods (from $\mathrm{p}<.05$ to $\mathrm{p}<.0001$ ). For both scores, the interaction group x period was not significant $(\mathrm{p}>.10)$ which revealed that patients performed lower than controls regardless of the period (i.e. flat graded deficit). Nevertheless, a floor effect in the EM score could have masked a temporal gradient. It is worth mentioning that most of the patients' recalls, regardless of their nature, were produced after many general clues and encouragements planned in the TEMPau task. 
Further analyses conducted on the percentage of each kind of memories (i.e., specific and detailed, specific, and generic, see Figure 2) ind icated main effect of group on the ratio of specific detailed and generic memories $(\mathrm{F}(1,36)=77.76$ and 97.84 , respectively, $\mathrm{p}<.0001)$, but no significant effect on the specific memories $(F(1,36)=2.96, p=.09)$. Neither the period effect nor the interaction period $\mathrm{x}$ group was significant. Despite promptings and encouragements to be specific, the patients produced higher percentages of generic memories whatever the time periods. They recalled repeated and extended events (e.g., "I did my national service at Vernon. We went for long walks, we did practice rounds. The food was not perfect and we needed to ask for a leave 8 days in advance") and vague events (e.g., "I did nothing special, I am always tired for holidays") not situated in time. In fact, $74 \%$ of their memories were generic memories (scored $\leq 2$ ), 16\% were specific (scored 3) and only 8\%, strictly episodic (scored 4). In comparison, the controls recalled 13\% of generic memories, $27 \%$ of specific memories and $60 \%$ of specific and detailed ones. This pattern of performances of patients is valid for remote as well as recent memories providing evidence of particular difficulties for recalling details from a specific encoding context, regardless of remoteness.

The analyses of the qualitative measurements of memories, the self-perspective and self-consciousness, indicated further significant differences between the patients and controls. Given the small sample size, these analyses were carried out using non parametrical tests. The Mann-Whitney $U$ test used to examine group effects for each period indicated that the percentage of observer responses for the seven patients who were capable to perform the task was higher compared to that of the control subjects for every time period $(p<.01)$ except the 0-17 period $(\mathrm{p}=.09)$. Overall, $56.8 \%$ of memories of the patients were reported using an observer perspective compared to $21.1 \%$ for controls. There was no significant group effect for field/observer and field responses, except for the last 5 years period $(p<.01)$ where the field responses were more numerous in controls than in patients. Otherwise, the mean 
percentages of remember and justified remember responses are presented in Figure 3 (top). Only nine patients were capable to perform this task. Regardless of the period, the MannWhitney $U$ test yielded significant main effects of group for remember responses $(p<.01)$ and justified ones $(\mathrm{p}<.001)$ with the exception of the percentage of justified responses for the $0-17$ period $(\mathrm{p}=.17)$. Taking into account the different kinds of content of memories (i.e. factual, spatial, and temporal, see Figure 3, bottom), the analysis confirmed the group effects regardless of the content and period apart from the $0-17$ period.

In summary, regardless of the remoteness and despite numerous general clues and encouragements, patients were particularly deficient in recalling event specific sensoryperceptual-affective details, i.e. ep isodic memories, providing instead more generic events than controls. They preferentially adopted an observer perspective during the retrieval of personal events instead of a field one and they showed a diminution of the subjective sense of remembering past events and capacity to relive sensory and/or affective details and spatiotemporal context.

Correlations between AM measures, general cognitive assessment and behavioural changes in $f v-F T D$

Given the extensive cognitive impairment revealed by the general cognitive examination, a variety of different mechanisms might contribute to AM impairment in fvFTD (see Matuszewski et al., 2006).

We examined the Spearman correlation coefficients between the percentage of gen eric (scored $\leq 2$ ) and specific (scored $\geq 3$ ) memories, combined on all time periods, and the different cognitive and behavioural measures. This analysis showed a significant link 1) between the percentage of specific memories and performances at the updating task (running span, $\mathrm{r}=.87, \mathrm{p}<.01)$ and 2$)$ between the percentage of generic memories and the DEX $(\mathrm{r}=.63$, 
$\mathrm{p}<.05)$. In order to better understand the relationships between $\mathrm{AM}$ and behavioural changes, we extended the intercorrelation analysis to the self-perspective and self-consciousness measures. We found significant relationships between the DEX and the self-perspective: positive with the observer responses $(\mathrm{r}=.88, \mathrm{p}<.01)$ and negative with the field/observer ones $(\mathrm{r}=-.74, \mathrm{p}<.01)$.

\section{Correlations between autobiographical memory scores and FDG-Uptake in $f v$-FTD}

Significant $(\mathrm{p}<.005$ uncorrected) positive correlations between the AM scores and normalized resting-state FDG-Uptake (Table 2, Figure 4) mainly concerned left-sided prefrontal cortex areas regardless of the time periods, more specially the orbital gyrus (BA 11 including ventrolateral area, BA 47), and, at a lesser degree, lateral temporal areas (BA 21/38). Several other correlations were also found, including the left dorsolateral frontal cortex (BA 6) for the 0-17 years and over 30 years periods, and the right orbital frontal cortex for the 0-17 years period. Scatter plots of the correlations for each period, in left orbitofrontal areas corresponding to the coordinates of the main peaks of each cluster, are shown in Figure 5.

Regarding the specific and generic memories, we mainly found sign ificant correlations between specific memories and the left orbital frontal cortex, and between generic memories and the left temporal pole (Table 3, Figure 6).

Finally, to deal the issue of the specificity of the role of orbitofrontal areas in AM retrieval, we looked at the correlations between all the general cognitive and behavioural scores and normalized resting-state FDG-Uptake. None of the scores was significantly correlated with the left orbitofrontal region (except the Running span for which we found a small cluster of significant correlations). 


\section{Discussion}

The aim of the present study was to unravel the neural bases of AM impairment in fv-FTD by mapping in a subgroup of patients previously studied (Matuszewski et al., 2006) the correlations between resting-state FDG-Uptake and measures of autobiographical memory (AM) across five life-time periods. The cognitivo-metabolic correlations revealed that AM deficits were mainly subserved by the dysfunction of the left-sided orbitofrontal cortex and also lateral temporal cortex regardless of the period. These results are discussed in line with the neuroimaging data and framework of AM.

\section{Characteristics and cognitive mechanisms of AM deficits in patients with fv-FTD}

As previously demonstrated in a group of $20 \mathrm{fv}$-FTD patients including the 13 present ones (Matuszewski et al., 2006), our data showed that AM impairment is characterized by an absence of gradient which means that the group effect is comparable for all lifetime periods demonstrating no difference between anterograde and retrograde periods (see also Hou et al., 2005; Nestor et al., 2002; Piolino et al., 2003; Thomas-Antérion et al., 2000). The comparison between the profiles of overall autobiographical memories (AM score) and strictly episodic ones (EM score) highlighted in fv-FTD the difficulty in retrieving truly episodic memories compared with more generic autobiographical ones despite the systematic clues and encouragements to be specific provided in our AM test. This result is consistent with previous studies of patients with non-progressive frontal injury revealing a deficit of executive function and of access to specific anterograde and retrograde autobiographical memories (Baddeley \& Wilson, 1986; Della Sala, Laiacona, Spinnler \& Trivelli, 1992; Kopelman, Stanhope \& Kingsley, 1999; Piolino et al., 2007; for reviews, see Conway and Fthenaki, 2000; Kopelman \& Kapur, 2001). The analysis of the different kinds of memories clearly showed that AM retrieval in fv-FTD was characterized by overgenerality, a tendency to recall repeated events (occurring more than one time) or extended events (lasting more than 1 day) rather than 
specific events. Unlike controls, the patients very rarely in itiated self-gen erative retrieval and recollected specific details from event-specific knowledge, even when they recalled a specific event located in time and space. Thus the recall in fv-FTD was characterized by underspecificity of AM and not only by difficulties for temporal information as previously reported (Thomas-Anterion et al., 2000).

Our results regarding the self-perspective and self-consciousness assessment during retrieval confirm this view and provide the first evidence of an impairment of both autono etic consciousness and self-perspective in fv-FTD. Only a subgroup of our patients could perform these tasks which required metamemory capacities that were shown to be impaired in fv-FTD (Souchay, Isingrini, Pillon \& Gil, 2003). As previously shown with remember responses (Piolino et al., 2003), the fv-FTD patients who were able to carry out this kind of selfjudgment, experienced difficulty to subjectively "feel" that they were mentally reliving the source of their memories. Moreover, they were unable to justify all their remember responses by providing as many episodic details as controls, not only about the temporal context but also about phenomenological (i.e. emotion, perception, thought) and spatial contexts. As regards the self-perspective, which was explored for the first time in fv-FTD using the field/observer paradigm, the majority of memories were classified as observer memories, unlike control subjects, regardless of time periods. This pattern of responses was in line with their difficulty in reporting and reliving episodic details, especially in terms of perceptual and affective details, and their inclination to instead report generic memories. Indeed, in general an observer perspective characterizes semanticized memories (Robinson and Swanson, 1993; Crawley and French, 2005; Nigro \& Neisser, 1983; Piolino et al., 2006), detachment from emotional content (D’Argembeau, Comblain \& Van der Linden, 2003; Nigro \& Neisser, 1983; Lemogne et al., 2006) and from the current self (Libby \& Eibach, 2002; Wilson \& Ross, 2003). These findings provide some view about the affective and cognitive (goals, 
beliefs) components of memories and self in fv-FTD. Because AM grounds the self by providing coherent narratives organized to elicit a sense of identity across the time (e.g., specific remembering may support the self as knowledgeable) (Conway et al., 2004), the fvFTD patients might experience discontinuity and fading of identity, like Alzheimer's disease (Addis \& Tippet, 2004).

Otherwise, the correlation study between AM performances, behavioural changes (DEX) and general cognitive measures confirmed and extended our previous study (Matuszewski et al., 2006), showing a link between overgenerality of AM (percentage of generic memories) as well as observer responses and behavioural changes in fv-FTD, which can reflect the severity of the fv-FTD pathology. We also found a link between specific memories and updating processes (i.e. running span). The role of updating function, which consists in continuously modifying the information already held in working memory, replacing old information with newer, external or internal incoming information (Morris and Jones, 1990), may be one of the important processes needed during the retrieval phase to generate specific AM from clues.

In brief, our cognitive data were consistent with the fact that the behavioural changes in fv-FTD patients, together with executive dysfunctions, are linked to the breakdown of AM, and therefore possibly to changes of identity (Conway et al., 2004; Wilson \& Ross, 2003; Addis \& Tippet, 2004; Matuszewski et al., 2006).

Neural bases of AM deficits in patients with fv-FTD

Our findings based on correlations between AM scores and resting normalized FDG-Uptake highlight the involvement of two left prefrontal areas, the main one being located in the orbitofrontal cortex (BA 11/47) and the other one in the dorsolateral (BA 6) region, and of the inferior lateral temporal lobe (left-sided for the three most remote periods, right-sided for the 
two most recent ones). These findings provide new insights on the cerebral network underpinning AM disruption in fv-FTD.

The left prefrontal cortex is involved in numerous functions related to AM retrieval, chiefly reconstructive memory processes and self-referential processes (for reviews, see Maguire, 2001; Conway, 2005; Gilboa, 2004; Svoboda et al., 2006). Moreover, this region has been found to be involved during AM tasks in most neuroimaging studies (see introduction). The involvement of two different parts of the left prefrontal cortex in the present study may reflect the intervention of distinct processes (Badre \& Wagner, 2004; Buckner \& Wheeler, 2001; Christoff \& Gabrieli, 2000; Fletcher \& Henson, 2001; Petrides, 2000; Umeda et al., 2005). Indeed, although both orbital and dorsolateral areas are thought to be associated with executive functioning (Cabeza \& Nyberg, 2000; Collette \& Van der Linden, 2002), the orbitofrontal cortex would appear to be more specifically involved in selecting, comparing and deciding on information in long-term memory (Lepage, Habib \& Tulving, 1998), while the dorsolateral frontal cortex would mediate the monitoring of output from long-term memory when several pieces of information in working memory need to be manipulated (Petrides, 2000). The role of the left orbitofrontal cortex seems to be more crucial in au tobiographical retrieval (Gilboa, 2004), which could be related to its involvement in behavioural regulation (Damasio, Grabowki, Frank, Galaburda \& Damasio, 1994; Wheeler \& Stuss, 2003), emotional processing (Markowitsch, Vandekerckhovel, Lanfermann \& Russ, 2003) or inhibition (Collette \& Van der Linden, 2002). In our study, this region did not appear to be implicated in any other cognitive or behavioural tasks (except the Running span at a small extent). However, our protocol did probably not include the specific tasks supported by this region, over and above the TEMPau task. Nevertheless, the link between the left orbitofrontal cortical area and the running span confirms the relationships between specific memories and updating processes. Consequently, the main correlation with the left 
orbitofrontal cortex is in keeping with the notion that this region plays a key role in au tobiographical memory retrieval (Gilboa, 2004, Svoboda et al., 2006), probably because our AM task requires the evaluation of internally generated information (Christoff \& Gabrieli, 2000) and in self-referential processes (i.e. representation, monitoring, evaluation and integration related to the self) (Craik, 1999; Frith \& Frith, 1999; Northoff \& Bermpohl, 2004). Our findings regarding the left dorsolateral cortex are consistent with its secondary involvement in AM reconstruction (Gilboa, 2004; Svoboda et al., 2006) and suggest that this region is required in case of high demands on monitoring processes for some time periods.

Apart from the left prefrontal cortex, the correlations between the AM scores and resting ${ }^{18} \mathrm{FDG}$ uptake in the whole brain concerned the anterior lateral temporal cortex including the polar area (BA 21/38). This finding may reflect the role of this region in semantic memory (Cabeza \& Nyberg, 2000). Williams and his colleagues (2005) showed that semantic breakdown in fv-FTD patients correlated with extensive loss of grey matter volume throughout the anterior temporal lobe. In the present study the percentage of generic memories was correlated with the left temporal pole. This finding is consistent with the involvement of the anterior temporal lobe in the cerebral network subtending AM retrieval (Maguire, 2001, Conway et al., 2002) because of its special role in process to construct an AM trace (Nadel \& Moscovitch, 1997; Conway et al., 2002; Markowitch, 1995).

Thus, our complete set of correlations can explain the mechanisms of AM disruption in fv-FTD mainly by a deficit in the generative/construction process in triggering off AMs, processes which are closely linked to left frontal lobe and temporal poles (Conway \& Fthenaki, 2000; Conway et al., 2002; Conway, 2005). Our results may be considered in line with Conway's model which proposes that the disruption of left prefrontal cortex network plays an important role in failure of complex self-referring memory tasks such as the 
construction of AM. This deficit might be linked to the failure of the "working self" (Conway \& Pleydell-Pearce, 2000), which usually acts as a part of working memory and generates a retrieval model accord ing to self-goals (activation of a general schematic representation of the self). These representations are subsequently used to direct searches of the personal knowledge base (distributed within networks in the lateral temporal areas) where a specific AM is eventually formed, supplying a sense of reliving. The left orbitofrontal network might be a plausible candidate for the cerebral substrate of the working self.

The present findings may not be due to an artefact of more advanced disease, since we studied correlations between metabolism and AM scores controlling age and the dementia severity. They reveal a specific pattern of correlations in fv-FTD as compared to Alzheimer's disease by means of a similar correlative approach between resting FDG-Uptake and AM scores. Indeed, in Alzheimer's disease the mechanisms of deficits (characterized by a Ribot's temporal gradient) involved hipocampus for recent AM (i.e. mainly anterograde memories) and prefrontal cortex for remote one (Eustache et al., 2004). By contrast, the present study supports the view that AM deficits in fv-FTD (characterized by a flat gradient) mainly depend on prefrontal and lateral temporal dysfunction, regardless of the period. This study highlights, therefore, the similarity of mechanisms of deficits for anterograde and retrograde memories in fv-FTD unlike Alzheimer's disease. This type of correlative approach in patients seems therefore a powerful approach to shed light on the mechanisms underlying different profiles of AM deficits reported in neuropsychological studies.

In conclusion, the present findings in fv-FTD substantiate the overriding contribution of dysexecutive disorders in AM, subtended by the left prefrontal cortex, and provide new insights showing the special role of the left orbital prefrontal cortex. This major left hemisphere involvement, which is in keeping with neuroimaging AM studies, contrasts with evidence of right hemisphere involvement in lesions studies (see introduction). The former 
may depend on the role of strategic searching for memory (involving executive and semantic verbal processes) which is strongly implicated in most of activation paradigms, whereas the latter may indicate the importance of phenomenal characteristics (emotion, spatial imagery, sense of reliving...) in measurements of AM recollection. Accordingly, neuro imaging findings show more bilateral involvement when there is sufficient time for recollection (e.g., see Graham et al., 2003). Finally, the discrepancy between the two approaches is only apparent, since AM is subtended by both hemispheres that together enable the re-experiencing of rich memories. In our study, the correlative approach allowed us to point out the components which explain the deficits. Moreover, our findings emphasized the contribution of a larger dysfunctional network involving the temporal neocortex which is also implicated in the construction of AM. 


\section{Acknowledgment}

The authors would like to thank for their assistance the cyclotron staff (GIP Cyceron of Caen) for their invaluable collaboration, the psychologists Alice Pélerin and Catherine Lalevée for their help in the examination of the patients and Philippe Conejero for the realization of the figures. 


\section{References}

Addis, R. A., \& Tippet, L. J. (2004). Memory of myself: Autobiographical memory and identity in Alzheimer's disease. Memory, 12, 56-74.

Baddeley, A. D. (1986). Working memory. Oxford: Clarendon Press.

Baddeley, A. D. (1997) Human memory: theory and practice. Hove, UK: Psychology Press.

Baddeley, A. D., \& Wilson, B. (1986). Amnesia, autobiographical memory and confabulation. In D. C. Rubin (Ed.), Autobiographical memory (pp. 225-252). Cambridge, England: Cambridge University Press.

Badre, D., \& Wagner, A. D. (2004). Selection, integration, and conflict monitoring: assessing the nature and gen erality of prefrontal cognitive control mechanisms. Neuron, 41, 473487.

Brazzelli, M., Colombo, N., Della Sala, S., \& Spinnler, H. (1994). Spared and impaired cognitive abilities after bilateral frontal damage. Cortex, 30, 27-51.

Brewer, W. (1996). What is recollective memory? In D. C. Rubin (Ed.), Remembering our past: Studies in autobiographical memory (pp. 19-66). Cambridge: Cambridge University Press.

Buckner, R. L., \& Wheeler, M. E. (2001). The cognitive neuroscience of remembering. Nature Review, Neuroscience, 2, 624-634.

Burt, C. D., Kemp, S., \& Conway, M. (2004). Memory for true and false autobiographical events description. Memory, 12, 545-552.

Cabeza, R., \& Nyberg, L. (2000). Imaging cognition II: an empirical review of 275 PET and fMRI studies. Journal of Cognitive Neuroscience, 12, 1-47.

Cardebat, D., Doyon, B., Puel, M., Goulet, P., \& Joanette, Y. (1990). Evaluation lexicale formelle et sémantique chez des sujets normaux. Performances et dynamique de 
production en fonction du sexe, de l'âge et du niveau. Acta Neurologica Belgica, 90, 207-217.

Chételat, G., Desgranges, B., de la Sayette, V., Viader, F., Berkouk, K., Landeau, B., et al. (2003). Dissociating atrophy and hypometabolism impact on memory in mild cognitive impairment. Brain, 126, 1955-1967.

Christoff, K., \& Gabrieli, J. D. E. (2000). The frontopolar cortex and human cognition: evidence for a rostrocaudal hierarchical organization within the human prefrontal cortex. Psychobiology, 28, 168-186.

Collette, F., \& Van der Linden, M. (2002). Brain imaging of the central executive component of working memory. Neuroscience and Biobehavioural Review, 26, 105-125.

Conway, M. A. (2005). Memory and the self. Journal of Memory and Language, 53, 594-628.

Conway, M. A., \& Fthenaki, A. (2000). Disruption and loss of autobiographical memory. In L. S. Cermak (Ed.), Handbook of neuropsychology: memory and its disorders (vol. 2, pp. 257-288). Amsterdam: Elsevier.

Conway, M. A., \& Pleydell-Pearce, C. W. (2000). The construction of autobiographical memories in the self-memory system. Psychological Review, 107, 261-288.

Conway, M. A., Pleydell-Pearce, C. W., \& Whitecross, S. E. (2001). The neuroanatomy of autobiographical memory: a slow cortical potential study of au tobiographical memory retrieval. Journal of Memory and Language, 45, 493-524.

Conway, M. A., Pleydell-Pearce, C. W., Whitecross, S. E., \& Sharpe, H. (2002). Brain imaging autobiographical memory. The Psychology of Learning and Motivation, 41, 229-263.

Conway, M. A., Singer, J. A., \& Tagini, A. (2004). The self and autobiographical memory: correspondence and coherence. Social Cognition, 22, 491-529. 
Craik, F. I. M. (1999). In search of the self. A PET study. Psychological Science, 10, 26-34.

Crawley, S. E., \& French, C. C. (2005). Field and observer viewpoint in remember/know memories of personal childhood events. Memory, 13, 673-681.

Dalla Barba, G. (1993). Confabulation: knowledge and recollective experience. Cognitive Neuropsychology, 10, 1-10.

Damasio, H., Grabowki, T., Frank, R., Galaburda, A. M., \& Damasio, A. R. (1994). The return of Phineas Gage: clues about the brain from the skull of a famous patient, Science, 264, 102-1105.

D’Argembeau, A., Comblain, C., \& Van der Linden, M. (2003). Phenomenal characteristic of autobiographical memories for positive, negative, and neutral events. Applied Cognitive Psychology, 17, 281-294.

Della Sala, S., Laiacona, M., Spinnler, H., \& Trivelli, C. (1992). Is autobiographical impairment due to a defict of recollection: an overview of studies of Alzheimer dements, frontal and global amnesia patients. In M. A.Conway, D. C. Rubin, H. Spinnler \& W. A. Wagenar (Eds.), Theoretical Perspectives on Autobiographical Memory (pp. 451-472). Dordrecht: Lüwer Academic Publishers.

Deloche, G., \& Hannequin, D. (1997). Test de dénomination orale d'images DO 80. Paris: Les Editions du Centre de Psychologie Appliquée.

Desgranges, B., Baron, J. C., Giffard, B., Chételat, G., Lalevée, C., Viader, F., et al. (2002). The neural basis of intrusions in free recall and cued recall: a PET study in Alzheimer's disease. Neuroimage, 17, 1658-1664.

Desgranges, B., Baron, J. C., Lalevée, C., Giffard, B., Viader, F., de la Sayette, V., et al. (2002). The neural substrates of episodic memory impairment in Alzheimer's disease as revealed by FDG-PET: relationship to degree of deterioration. Brain, 125, 11161124. 
Eustache, F., Desgranges, B., Giffard, B., de la Sayette, V., \& Baron, J. C. (2001). Entorhinal cortex disruption causes memory deficit in early Alzheimer's disease as shown by PET. NeuroReport, 12, 683-685.

Eustache, F., Piolino, P., Giffard, B., Viader, F., de la Sayette, V., Baron, J.C., et al. (2004). 'In the course of time': a PET study of the cerebral substrates of autobiographical amnesia in Alzheimer's disease. Brain, 127, 1549-1560.

Fletcher, P. C., \& Henson, R. N. (2001). Frontal lobe and human memory. Insights from functional neuroimaging. Brain, 124, 849-881.

Folstein, M. F., Folstein, S. E., \& McHugh, P. R. (1975). "Mini Mental State": A practical method for grading the cognitive state of patients for the clinician. Journal of Psychiatric Research, 12, 189-198.

Frith, C. D., \& Frith, U. (1999). Interacting minds - a biological basis. Science, 286, 16921695.

Gardiner, J. M. (1988). Functional aspects of recollective experience. Memory and Cognition, $16,309-313$.

Giffard, B., Desgranges, B., Nore-Mary, F., Lalevée, C., de la Sayette, V., Pasquier, F., et al. (2001). The nature of semantic memory deficits in Alzheimer's disease: new insights from hyperpriming effects. Brain, 124, 1522-1532.

Gilboa, A. (2004). Autobiographical and episodic memory-one and the same? Evidence from prefrontal activation in neuroimaging studies. Neuropsychologia, 42, 1336-1349.

Gilboa, A., Winocur, G., Grady, C. L., Hevenor, S. J., \& Moscovitch, M. (2004). Remembering our past: functional neuroanatomy of recollection of recent and very remote personal events. Cerebral Cortex, 14, 1214-1225. 
Graham, K.S., Lee, A.C., Brett, M., \& Patterson, K. (2003). The neural basis of autobiographical and semantic memory: new evidence from three PET studies. Cognitive, Affective \& Behavioral Neuroscience, 3, 234-254.

Gregory, C., Lough, S., Stone, V., Erzinclioglu, S., Martin, L., Baron-Cohen, S., et al. (2002). Theory of mind in patients with frontal variant frontotemporal dementia and Alzheimer's disease: theoretical and practical implications. Brain, 125, 752-764.

Grober, E., \& Buschke, H. (1987). Genuine memory deficits in dementia. Developmental Neuropsychology, 3, 13-36.

Hodges, J. R., \& Gurd, J. M. (1994). Remote memory and lexical retrieval in a case of frontal Pick's disease. Archives of Neurolology, 51, 821-827.

Hodges, J. R., Patterson, K., Ward, R., Garrard, P., Bak, T., Perry, R., et al. (1999). The differentiation of semantic dementia and frontal lobe dementia (temporal and frontal variants of fronto-temporal dementia) from early Alzheimer's disease: a comparative neuropsychological study. Neuropsychology, 13, 31-40.

Hodges, J. R., \& Miller, B. (2001). The neuropsychology of frontal variant frontotemporal dementia and semantic dementia. Introduction to the special topic papers: Part II. Neurocase, 7, 113-121.

Hou, C. E., Miller, B. L., \& Kramer, J. H. (2005). Patterns of autobiographical memory loss in dementia. International Journal of Geriatric Psychiatry, 20, 809-815.

Kopelman, M. D., Stanhope, N., \& Kingsley, D. (1999). Retrograde amnesia in patients with diencephalic, temporal lobe or frontal lesions. Neuropsychologia, 37, 939-958.

Kopelman, M. D., \& Kapur, N. (2001). The loss of episodic memories in retrograde amnesia: single-case and group studies. Philosophical transactions of the Royal Society of London. Series B, Biological sciences, 356, 1409-1421. 
Kopelman, M. D., Lasserson, D., Kingsley, D. R., Bello, F., Rush, C., Stanhope, N., et al. (2003). Retrograde amnesia and the volume of critical brain structures. Hippocampus, 13, 879-891.

Kramer, J. H., Jurik, J., Sha, S. J., Rankin, K. P., Rosen, H. J., Johnson, J. K., et al. (2003). Distinctive neuropsychological patterns in frontotemporal dementia, semantic dementia, and Alzheimer disease. Cognitive and Behavioral Neurology, 16, 211-218.

Lemogne, C., Piolino, P., Friszer, S., Claret, A., Girault, N., Jouvent, R., et al. (2006). Episodic autobiographical memory in depression: Specificity, autonoetic consciousness, and self-perspective. Consciousness and Cognition, 15, 258-268.

Lepage, M., Habib, R., \& Tulving, E. (1998). Hippocampal PET activations of memory encoding and retrieval: the HIPER model. Hippocampus, 8, 313-322.

Libby, L. K., \& Eibach, R. P. (2002). Looking back in time: Self-concept change affects visual perspective in autobiographical memory. Journal of Personality and Social Psychology, 82, 167-179.

Lough, S., Gregory, C., \& Hodges, J. R. (2001). Dissociation of social cognition and executive function in frontal variant frontotemporal dementia. Neurocase, 7, 123-130.

Maguire, E. A. (2001). Neuroimaging studies of autobiographical event memory. Philosophical transactions of the Royal Society of London. Series B, Biological sciences, 356, 1441-1451.

Maguire E. A., \& Frith C. D. (2003). Aging affects the engagement of the hippocampus during autobiographical memory retrieval. Brain, 126, 1511-1523.

Markowitsch, H. J. (1995). Which brain regions are critically involved in the retrieval of old episodic memory? Brain Research Review, 21, 117-127. 
Markowitsch, H. J., Vandekerckhovel, M. M., Lanfermann, H., \& Russ, M. O. (2003). Engagement of lateral and medial prefrontal areas in the ecphory of sad and happy autobiographical memories. Cortex, 39, 643-665.

Matuszewski, V., Piolino, P., de la Sayette, V., Lalevée, C., Pélerin, A., Dupuy, B. et al. (2006). Retrieval mechanisms for autobiographical memories: Insights from the frontal variant of fron totemporal dementia, Neuropsychologia, 44, 2386-2397.

Miller, B. L., Seeley, W. W., Mychack, P., Rosen, H. J., Mena, I., \& Boone, K. (2001). Neuroanatomy of the self. Evidence from patients with frontotemporal dementia. Neurology, 57, 817-821.

Miyake, A., Friedman, N. P., Emerson, M. J., Witzki, A. H., Howerter, A., \& Wager TD. (2000). The unity and diversity of executive functions and their contributions to complex "frontal lobe" tasks: a latent variable analysis. Cognitive Psychology, 41, 49100.

Morris, N., \& Jones, D. M. (1990). Memory updating in working memory: the role of the central executive. British Journal of Psychology, 81, 111-121.

Müller-Gartner, H. W., Links, J. M., Prince, J. L., Bryan, R. N., McVeigh, E., Leal, J. P., et al. (1992). Measurement of radiotracer concentration in brain gray matter using positron emission tomography: MRI-based correction for partial volume effects. Journal of Cerebral Blood Flow Metabolism, 12, 571-583.

Mychack, P., Kramer, J. H., Boone, K. B., \& Miller, B. L. (2001). The influence of right frontotemporal dysfunction on social behavior in frontotemporal dementia. Neurology, 56, S $11-5$.

Nadel, L., \& Moscovitch, M. (1997). Memory consolidation, retrograde amnesia and the hippocampal complex. Current Opinion in Neurobiology, 7, 217-227. 
Neary, D., Snowden, J.S., Gustafson, L., Passant, U., Stuss, D., Black, S., et al. (1998). Frontotemporal lobar degeneration: a consensus on clinical diagnostic criteria. Neurology, 51, 1546-1554.

Nestor, P. J., Graham, K. S., Bozeat, S., Simons, J. S., \& Hodges, J. R. (2002). Memory consolidation and the hippocampus: further evidence from studies of autobiographical memory in semantic dementia and frontal variant of frontotemporal dementia. Neuropsychologia, 40, 633-654.

Nigro, G., \& Neisser, U. (1983). Point of view in personal memories. Cognitive Psychology, 15, 467-482.

Northoff, G., \& Bermpohl, F. (2004). Cortical midline structures and the self. Trends in Cognitive Sciences, 8, 102-107.

Perani, D., Bressi, S., Cappa, S.F., Vallar, G., Alberoni, M., Grassi, F., et al. (1993). Evidence of multiple memory system in the human brain. A [18F]FDG PET metabolic study. Brain. 116, 903-919.

Perry, R. J., \& Hodges, J. R. (2000). Differentiating frontal and temporal variant frontotemporal dementia from Alzheimer's disease. Neurology, 54, 2277-2284.

Petrides, M. (2000). Frontal lobe and memory. In F. Boller \& J. Grafman (Eds), Handbook of neuropsychology (Vol 2, 2nd ed., pp. 67-84). Amsterdam: Elsevier.

Piolino, P., Desgranges, B., Belliard, S., Matuszewski, V., Lalevée, C., de la Sayette, V., et al. (2003). Autobiographical memory and autonoetic consciousness: triple dissociation in neurodegen erative diseases. Brain, 126, 2203-2219.

Piolino, P., Giffard-Quillon, G., Desgranges, B., Chételat, G., Baron, J-C., \& Eustache, F. (2004). Re-experiencing old memories via hippocampus: a PET study of autobiographical memory. Neuroimage, 22, 1371-1383. 
Piolino, P., Desgranges, B., Clarys, D., Guillery-Girard, B., Taconat, L., Isingrini, \& M., Eustache, F. (2006). Autobiographical memory, autonoetic consciousness and selfperspective in aging. Psychology and Aging, 3, 510-525.

Piolino, P., Desgranges, B., Manning, L., North, P., Jokic, F., \& Eustache, F. (2007). Autobiographical memory, the sense of recollection and executive functions after severe closed head injury. Cortex, 43, 176-195.

Quarantelli, M., Berkouk, K., Prinster, A., Landeau, B., Svarer, C., Balkay, L., et al. (2004). Integrated software for the analysis of brain PET/SPECT studies with partial-volumeeffect correction. Journal of Nuclear Medecine, 45, 192-201.

Quinette, P., Guillery, B., Desgranges, B., de la Sayette, V., Viader, F., \& Eustache, F. (2003). Working memory and executive functions in transient global amnesia. Brain, $126,1917-1934$.

Ratnavalli E., Brayne C., Dawson K., \& Hodges J. R. (2002). The prevalence of frontotemporal dementia. Neurology, 58, 1615-1621.

Rauchs, G., Piolino, P., Mézenge, F., Landeau, B., Lalevée, C., Pélerin, et al.. (in press). Autonoetic consciousness in Alzheimer's disease: neuropsychological and PET findings using an episodic learning and recognition task. Neurobiology of Aging. [Epub ahead of print].

Reed, L. J., Lasserson, D., Marsden, P., Bright, P., Stanhope, N., \& Kopelman, M. D. (2005). Correlations of regional cerebral metabolism with memory performance and executive function in patients with herpes encephalitis or frontal lobe lesions. Neuropsychology, $19,555-565$. 
Reitan, R. M. (1958). Validity of the trail making test as an indication of organic brain damage. Perception and Motor Skills, 8, 271-276.

Robinson, J. A., \& Swanson, S. (1993). Autobiographical memory: The next phase. Applied Cognitive Psychology, 4, 321-335.

Rosen, H. J., Narvaez, J. M., Hallam, B., Kramer, J. H., Wyss-Coray, C., Gearhart, R., et al., (2004). Neuropsychological and functional measures of severity in Alzheimer disease, frontotemporal dementia, and semantic dementia. Alzheimer's Disease and Associated Disorders, 18, 202-207.

Rousset, O. G., Ma, Y., \& Evans, A.C. (1998). Correction for partial volume effects in PET: principle and validation. Journal of Nuclear Medecine, 39, 904-911.

Rubin, D. C., \& Greenberg, D. L. (1998). Visual memory-deficit amnesia: a distinct amnesic presentation and etiology. Proceedings of the National Academy of Sciences, USA, 95, 5413-5416.

Salmon, E., Garraux, G., Delbeuck, X., Collette, F., Kalbe, E., Zuendorf, G., et al. (2003). Predominant ventromedial frontopolar metabolic impairment in frontotemporal dementia. Neuroimage, 20, 435-440.

Sarazin, M., Pillon, B., Giannakopoulos, P., Rancurel, G., Samson, Y., \& Dubois, B. (1998). Clinicometabolic dissociation of cognitive functions and social behaviour in frontal lesions. Neurology, 51, 142-148.

Schroeter, M. L., Raczka, K., Neumann, J., \& von Cramon, D. Y. (in press). Neural networks in frontotemporal dementia-A meta-analysis. Neurobiology of Aging [Epub ahead of print].

Snowden, J. S., Bath gate, D., Varma, A., Blackshaw, A., Gibbons, Z. C., \& Neary, D. (2001). Distinct behavioural profiles in frontotemporal dementia and semantic dementia. Journal of Neurology, Neurosurgery and Psychiatry, 70, 323-332. 
Snowden, J. S., Neary, D., \& Mann, D. M. (2002). Frontotemporal dementia. British Journal of Psychiatry, 180, 140-143.

Souchay, C., Isingrini, M., Pillon, B., \& Gil, R. (2003). Metamemory accuracy in Alzheimer's disease and frontotemporal lobe dementia. Neurocase, 6, 482-492.

Steinvorth, S., Corkin, S., \& Halgren, E. (2006). Ecphory of autobiographical memories: an fMRI study of recent and remote memory retrieval. Neuroimage. 30, 285-298.

Stroop, J.R. (1935). Studies of interference in serial verbal reactions. Journal of Experimental Psychology, 18, 643-662.

Svoboda, E., \& McKinnon, M. C., \& Levine, B. (2006). The functional neuroanatomy of autobiographical memory: A meta-analysis. Neuropsychologia, 44, 2189-2208.

Thomas-Antérion, C., Jacquin, K., \& Laurent, B. (2000). Differential mechanisms of impairment of remote memory in Alzheimer's and Frontotemporal dementia. Dementia and Geriatric Cognitive Disorders, 11, 100-106.

Tomaszewski Farias, S., \& Jagust, W .J. (2004). Neuroimaging in non-Alzheimer dementias. Clinical Neuroscience Research, 383-395.

Tröster, A. I., Warmflash, V., Osorio, I., Paolo, A. M., Alexander, L., \& Barr, W. B. (1995). The roles of semantic networks and search efficiency in verbal fluency performance in intractable temporal lobe epilepsy. Epilepsy Research, 21, 19-26.

Tulving, E. (1985). Memory and consciousness. Canadian Psychology, 25, 1-12.

Tulving E. (2001). Episodic and common sense: how far apart? Philosophical transactions of the Royal Society of London. Series B, Biological sciences, 356, 1505-1515.

Tzourio-Mazoyer, N., Landeau, B., Papathanassiou, D., Crivello, F., Etard, O., Delcroix, N., et al. (2002). Automated anatomical labeling of activations in SPM using a 
macroscopic anatomical parcellation of the MNI MRI single-subject brain. Neuroimage, 15, 273-289.

Umeda, S., Akine, Y., Kato, M., Muramatsu, T., Mimura, M., Kandatsu, S., et al. (2005). Functional network in the prefrontal cortex during episodic memory retrieval. Neuroimage, 26, 932-940.

Viard, A., Piolino, P., Desgranges, B., Lebreton, K., Chételat, G., Landeau, B., et al., (in press). Autobiographical memories and sense of recollection over the entire lifetime of elderly subjects: an fMRI study. Cerebral Cortex [Epub ahead of print].

Wechsler, D. (1969). Echelle clinique de mémoire (forme1). Paris: Centre de Psychologie Appliquée.

Wheeler, M. A., Stuss, D. T., \& Tulving, E. (1997). Toward a theory of episodic memory: The frontal lobes and autonoetic consciousness. Psychological Bulletin, 121, 331-354.

Wheeler, M. A., \& Stuss, D. T. (2003). Remembering and knowing in patients with frontal lobe injuries. Cortex, 39, 827-846.

Williams, G. B., Nestor, P. J., \& Hodges, J. R. (2005). Neural correlates of semantic and behavioural deficits in frontotemporal dementia. Neuroimage, 24, 1042-1051.

Wilson, A. E., \& Ross, M. (2003). The identity function of autobiographical memory: time is on our side. Memory, 11, 137-149.

Wilson, B. A., Alderman, N., Burgess, P., Emslie, H., \& Evans, J. J. (1996). Behavioural assessment of the dysexecutive syndrome (BADS). Bury St Edmunds: Thames Valley Test Company. 
Table 1. Neuropsychological data (mean and SD) for 13 FTD and 21 control subjects

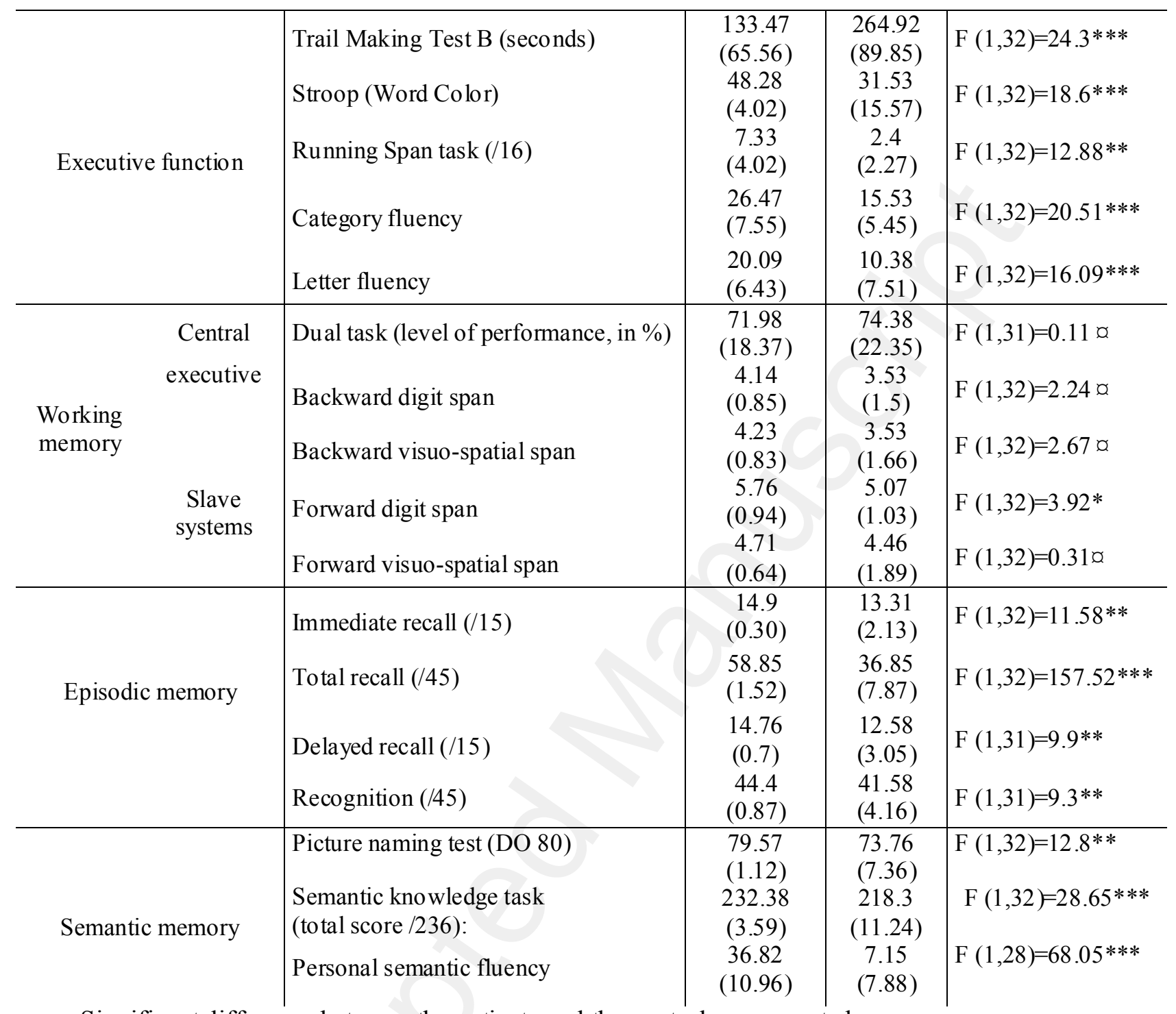

Significant difference between the patients and the controls are reported.

$* \mathrm{p}<.05 ; * * \mathrm{p}<.01 ; * * * \mathrm{p}<.001$ 
Table 2. Main peaks of significant ( $\mathrm{p}<.005$, uncorrected, SPM maps thresholded at T $>3.36$, $\mathrm{Z}>2.60$, minimal cluster size $\mathrm{k}>100$ voxels) correlations between $\mathrm{AM}$ score according to time period and FDG-Uptake using the statistical parametric mapping method. The clusters are listed in decreasing order of peak $\mathrm{Z}$ score adjusted to MNI space

\begin{tabular}{|c|c|c|c|c|c|c|c|}
\hline \multirow[t]{2}{*}{ Periods } & \multirow[t]{2}{*}{$\mathrm{k}$} & \multirow[t]{2}{*}{ label } & \multirow[t]{2}{*}{ BA } & \multicolumn{3}{|c|}{ MNI coordinates } & \multirow[t]{2}{*}{ Z } \\
\hline & & & & $\mathrm{x}$ & $\mathrm{y}$ & $\mathrm{z}$ & \\
\hline \multirow[t]{14}{*}{$0-17$} & \multirow[t]{5}{*}{14441} & $\mathrm{~L}$ mid frontalG, orbital & 11 & -8 & 55 & -24 & 4.15 \\
\hline & & L sup frontal G, orbital & 11 & -16 & 50 & -19 & 3.67 \\
\hline & & $\mathrm{L}$ inf frontal $\mathrm{G}$, orbital & 47 & -47 & 41 & -10 & 3.57 \\
\hline & & $\mathrm{L}$ med frontal $\mathrm{G}$, orbital & & & & & \\
\hline & & $\mathrm{L}$ rectus $\mathrm{G}$ & & & & & \\
\hline & \multirow[t]{2}{*}{2459} & L sup frontal $\mathrm{G}$, dorsolateral & $6 / 32$ & -15 & 14 & 44 & 3.74 \\
\hline & & $\mathrm{L}$ mid frontal $\mathrm{G}$ & $44 / 48$ & -33 & 22 & 28 & 3.17 \\
\hline & \multirow[t]{2}{*}{606} & L sup temporal G, pole & 38 & -56 & 7 & -3 & 3.34 \\
\hline & & $\mathrm{L}$ roland ic operculum & & & & & \\
\hline & \multirow[t]{3}{*}{2951} & $\mathrm{R}$ mid frontal $\mathrm{G}$, orbital & 11 & 28 & 37 & -21 & 3.32 \\
\hline & & $\mathrm{R}$ inf frontal $\mathrm{G}$, orbital & 47 & 42 & 46 & -17 & 3.21 \\
\hline & & $\mathrm{R}$ sup frontal $\mathrm{G}$, orbital & & & & & \\
\hline & 422 & $\mathrm{R}$ rolandic operculum & 48 & 49 & 4 & 17 & 2.86 \\
\hline & 380 & $\begin{array}{l}R \text { inf frontal } G \text {, triangular } \\
R \text { inf frontal } G \text {, orbital }\end{array}$ & 45 & 54 & 40 & -2 & 2.85 \\
\hline \multirow[t]{6}{*}{$18-30$} & \multirow[t]{4}{*}{6318} & L sup frontal G, orbital & 11 & -15 & 46 & -16 & 3.84 \\
\hline & & $\mathrm{L}$ rectus $\mathrm{G}$ & 11 & -17 & 28 & -25 & 3.56 \\
\hline & & $\mathrm{L}$ mid frontal $\mathrm{G}$, orbital & 11 & -10 & 63 & -21 & 2.64 \\
\hline & & $\mathrm{L}$ med frontal $\mathrm{G}$, orbital & & & & & \\
\hline & \multirow[t]{2}{*}{1912} & $\mathrm{~L}$ mid temporalG & 37 & -65 & -55 & -4 & 3.38 \\
\hline & & $\mathrm{L}$ inf temporal $\mathrm{G}$ & 21 & -69 & -33 & -14 & 2.99 \\
\hline \multirow[t]{15}{*}{ Over 30} & \multirow[t]{4}{*}{1848} & L sup temporalG, pole & 38 & -57 & 10 & -5 & 4.08 \\
\hline & & $\mathrm{L}$ inf frontal G, opercular & 44 & -59 & 20 & 12 & 2.97 \\
\hline & & L roland ic operculum & & & & & \\
\hline & & $\mathrm{L}$ inf frontal $\mathrm{G}$, triangular & & & & & \\
\hline & 466 & L supramarg inal & 48 & -68 & -38 & 26 & 4.04 \\
\hline & \multirow[t]{3}{*}{4669} & $\mathrm{~L}$ inf frontal $\mathrm{G}$, orbital & 47 & -49 & 42 & -9 & 3.72 \\
\hline & & $\mathrm{L}$ inf frontal $\mathrm{G}$, triangu lar & 47 & -46 & 28 & -7 & 3.65 \\
\hline & & L mid frontal G, orbital & & & & & \\
\hline & 1441 & L sup frontal $\mathrm{G}$, orbital & 11 & -11 & 55 & -26 & 3.51 \\
\hline & & L Rectus & & & & & \\
\hline & \multirow[t]{4}{*}{2121} & L sup frontal $\mathrm{G}$, dorsolateral & 6 & -12 & 4 & 46 & 3.31 \\
\hline & & $\mathrm{L}$ mid frontal $\mathrm{G}$ & 6 & -27 & 7 & 43 & 2.87 \\
\hline & & L superior motor area & & & & & \\
\hline & & L mid cingulate & & & & & \\
\hline & 733 & L sup frontal $\mathrm{G}$, dorsolateral & 6 & -28 & 66 & -4 & 3.21 \\
\hline
\end{tabular}




\begin{tabular}{|c|c|c|c|c|c|c|c|}
\hline & & $\begin{array}{l}\text { L sup frontal } G \text {, orbital } \\
\text { L mid frontal } G\end{array}$ & & & & & \\
\hline \multirow{6}{*}{$\begin{array}{l}\text { Last } 5 \\
\text { years }\end{array}$} & 1413 & $\mathrm{~L}$ mid frontal $\mathrm{G}$, orbital & 11 & -20 & 50 & -22 & 3.75 \\
\hline & & L sup frontal G, orbital & 11 & -10 & 56 & -26 & 3.14 \\
\hline & 378 & L sup temporalG, pole & 38 & -58 & 9 & -5 & 3.67 \\
\hline & & L roland ic operculum & & & & & \\
\hline & 424 & $\mathrm{R}$ mid temporal $\mathrm{G}$ & 21 & 70 & -26 & -5 & 3.21 \\
\hline & & R sup temporal G & & & & & \\
\hline \multirow{4}{*}{$\begin{array}{l}\text { Last } 12 \\
\text { months }\end{array}$} & 1451 & $\mathrm{R}$ mid temporal $\mathrm{G}$ & 21 & 69 & -23 & -6 & 4.43 \\
\hline & & R sup temporal G & & & & & \\
\hline & 1579 & $\mathrm{~L}$ mid frontal $\mathrm{G}$, orbital & 11 & -20 & 47 & -23 & 3.71 \\
\hline & & L sup frontal $G$, orbital & & & & & \\
\hline
\end{tabular}

BA : Brodmann's area; $\mathrm{x}, \mathrm{y}, \mathrm{z}$ : coordinates of peaks in Talairach's system ; L : Left $; \mathrm{R}$ : right; G: gyrus

Cluster size is indicated by $\mathrm{k}=$ number of voxels in the particular cluster $(\mathrm{k}>100)$. Labels were obtained using the aal toolbox (see method). 
Table 3. Main peaks of significant ( $\mathrm{p}<.005$, uncorrected, SPM maps thresholded at $\mathrm{T}>3.36$, $\mathrm{Z}>2.60$, minimal cluster size $\mathrm{k}>100$ voxels) correlations between the percentage of specific and generic memories combined on all time periods and FDG-Uptake. The clusters are listed in decreasing order of peak Z score adjusted to MNI space

\begin{tabular}{|c|c|c|c|c|c|c|c|}
\hline \multirow{2}{*}{$\begin{array}{l}\text { Kinds of } \\
\text { memories }\end{array}$} & \multirow[t]{2}{*}{$\mathrm{k}$} & \multirow{2}{*}{ label } & \multirow{2}{*}{ BA } & \multicolumn{3}{|c|}{ MNI coordinates } & \multirow[t]{2}{*}{ Z } \\
\hline & & & & $x$ & $\mathrm{y}$ & $\mathrm{z}$ & \\
\hline Specific & 109 & $\begin{array}{l}\text { Linf frontal G, orbital } \\
\text { L sup frontal G, orbital } \\
\text { L mid frontal G, orbital } \\
\text { L med frontal G, orbital } \\
\text { L caud ate }\end{array}$ & $47 / 11$ & -38 & 38 & -10 & 3.41 \\
\hline Generic & $\begin{array}{l}102 \\
369\end{array}$ & $\begin{array}{l}\text { L sup temporal G, pole } \\
\text { L caud ate } \\
\text { L putamen } \\
\text { L insula } \\
\text { L sup frontal G, orbital } \\
\text { L rectus }\end{array}$ & $\begin{array}{c}38 \\
11 / 47\end{array}$ & $\begin{array}{l}-54 \\
-20\end{array}$ & 20 & $\begin{array}{l}-14 \\
-14\end{array}$ & $\begin{array}{l}3.91 \\
3.33\end{array}$ \\
\hline
\end{tabular}

BA : Brodmann's area ; $\mathrm{x}, \mathrm{y}, \mathrm{z}$ : coordinates of peaks in Talairach's system ; L : Left ; R : right; G: gyrus

Cluster size is indicated by $\mathrm{k}=$ number of voxels in the particular cluster $(\mathrm{k}>100)$. Labels were obtained using the aal toolbox (see method). 


\section{Legends of the figures}

Figure 1. Performances on autobiographical memory task (AM and EM scores) according to the time period for FTD and 25 controls subjects.

Figure 2. The mean percentage of different kinds of memories (specific and detailed, specific, and generic) as a function of group and lifetime period.

Figure 3. The mean percentage of remember responses (a left) and justified remember responses for lifetime periods all contents combined (a right) and according to the content (factual, spatial, temporal) tested (b).

Figure 4. SPM2 maps of significant correlations between autobiographical memory score and FDG-Uptake according to time period, controlling for the confounding effects of age and dementia severity (MMSE score) $(\mathrm{p}<0.005$ uncorrected). The significant correlations are shown as colored voxels superimposed on to axial slices of the customized template. The right hemisphere corresponds to the right side of the figure.

A: period 0-17 years old; B: period 18-30 years old; C: period over 30; D: last 5 years; E: last 12 months

Figure 5. Scatter plots of the correlations between FDG-Uptake values and the autobiographical memory scores for each period, in left orbitofrontal areas (coordinates of main peak of cluster size).

Figure 6. SPM2 maps of significant correlations between the percentage of specific and generic memories, all time periods combined, and FDG-Uptake controlling for the confounding effects of age and dementia severity (MMSE score) $(\mathrm{p}<0.005$ uncorrected). For anatomical orientation, the significant correlations are shown as colored voxels superimposed onto a customized template based on the whole group of subject. The right hemisphere corresponds to the right side of the figure. The cross indicates the locus of the main correlation ( $\mathrm{Z}$ values). 


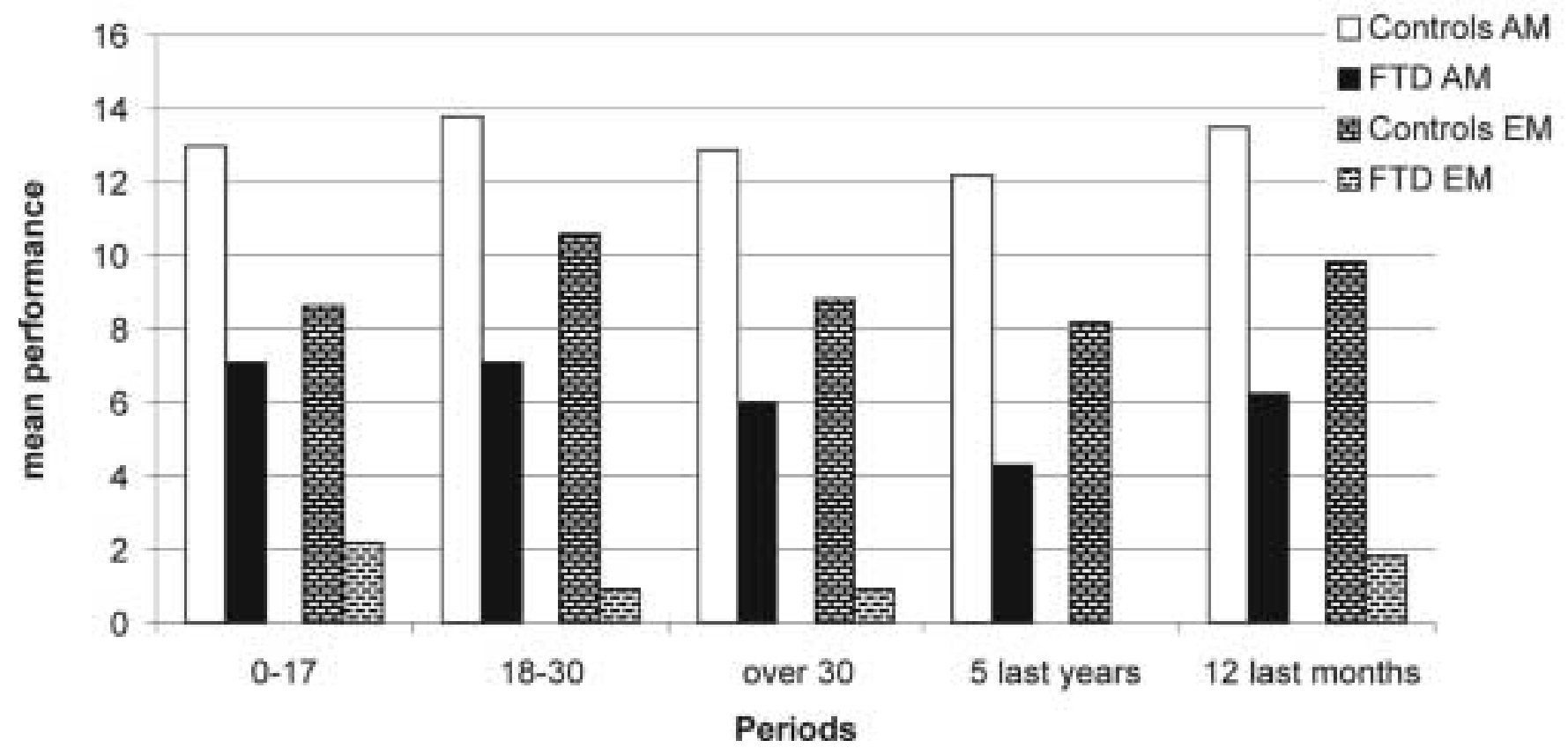

Page 44 of 


\section{specific detailed memories}

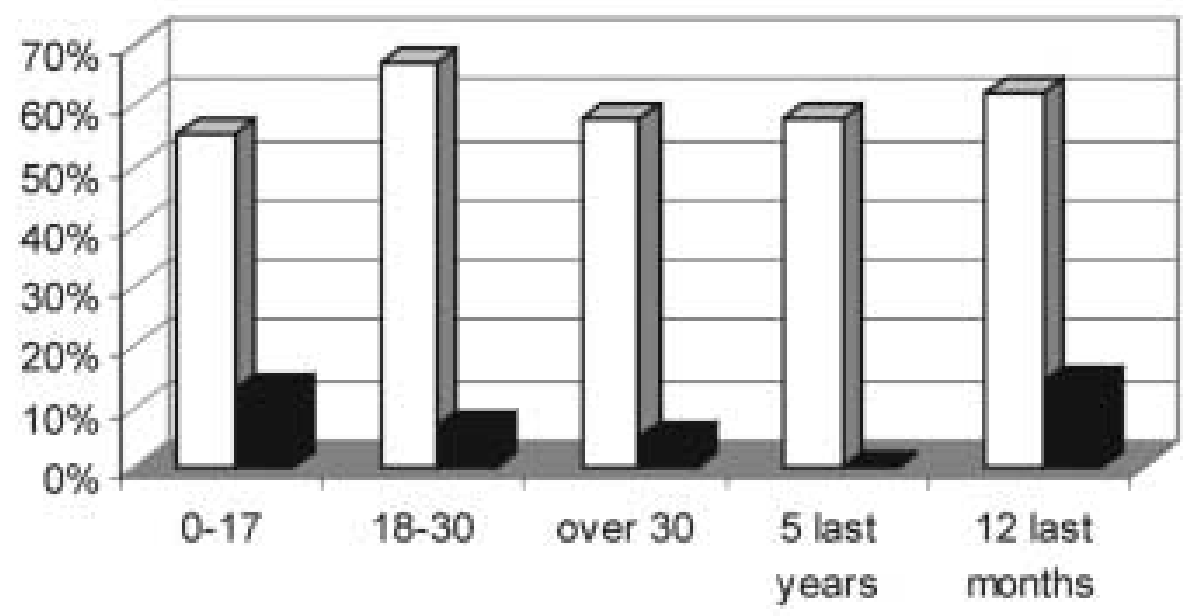

$\square$ Controls

aTD

specific memories

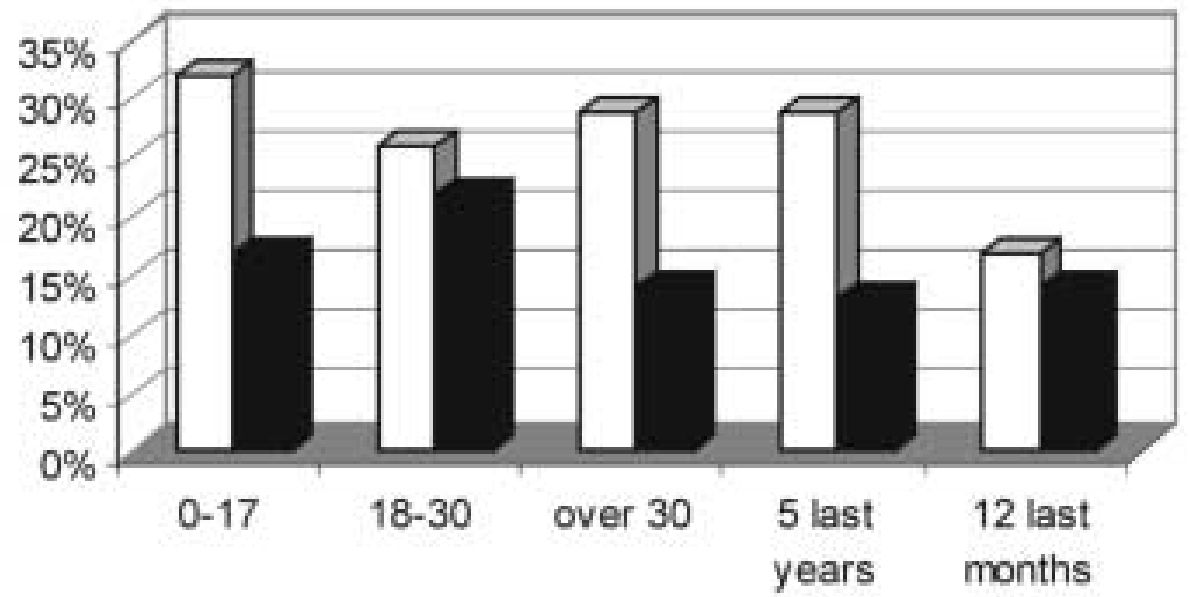

generic memories

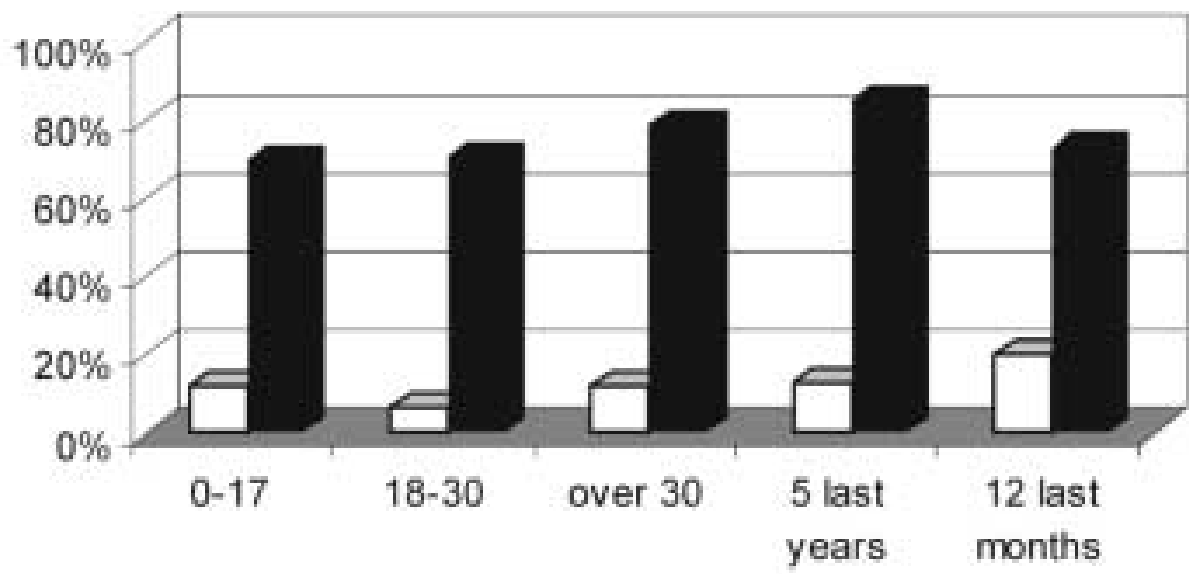




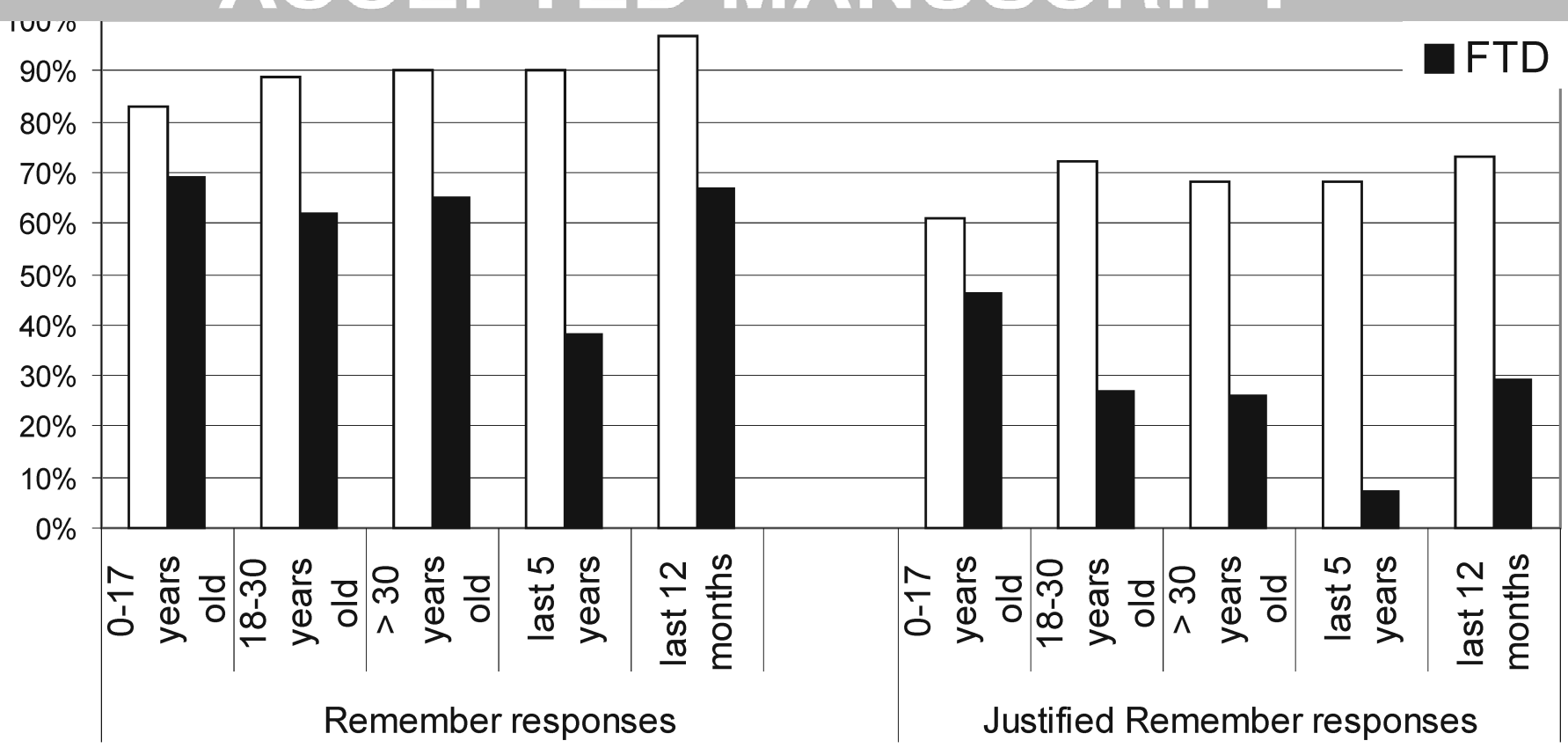

$\square$ Controls

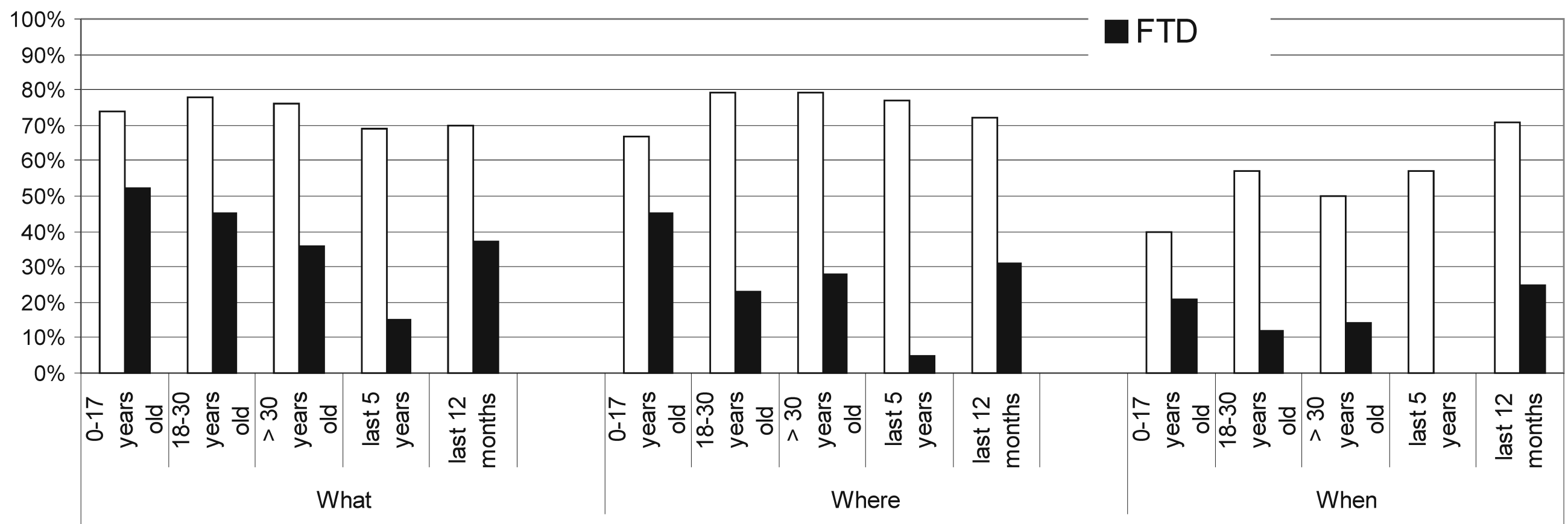




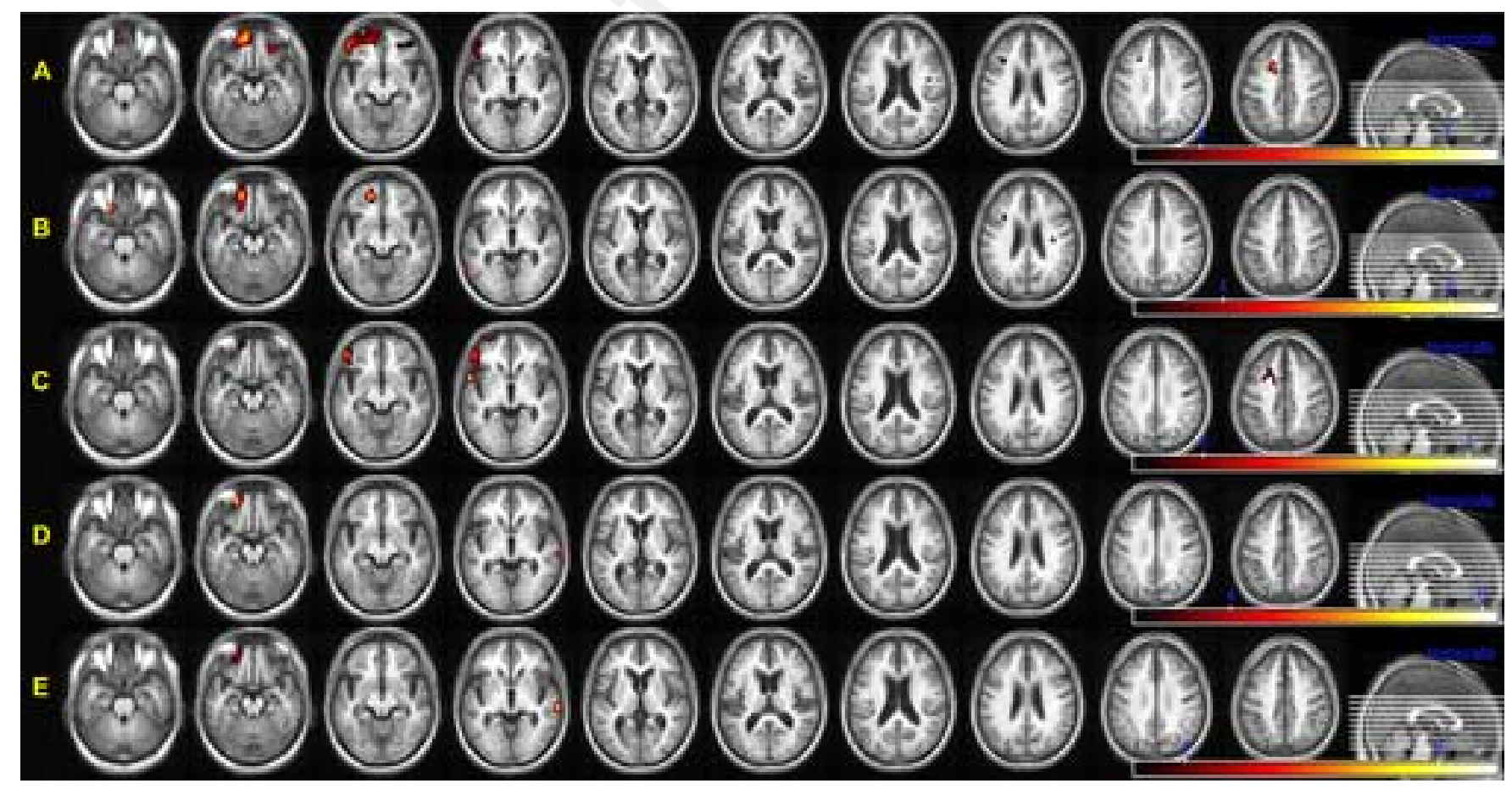

Page 47 of 

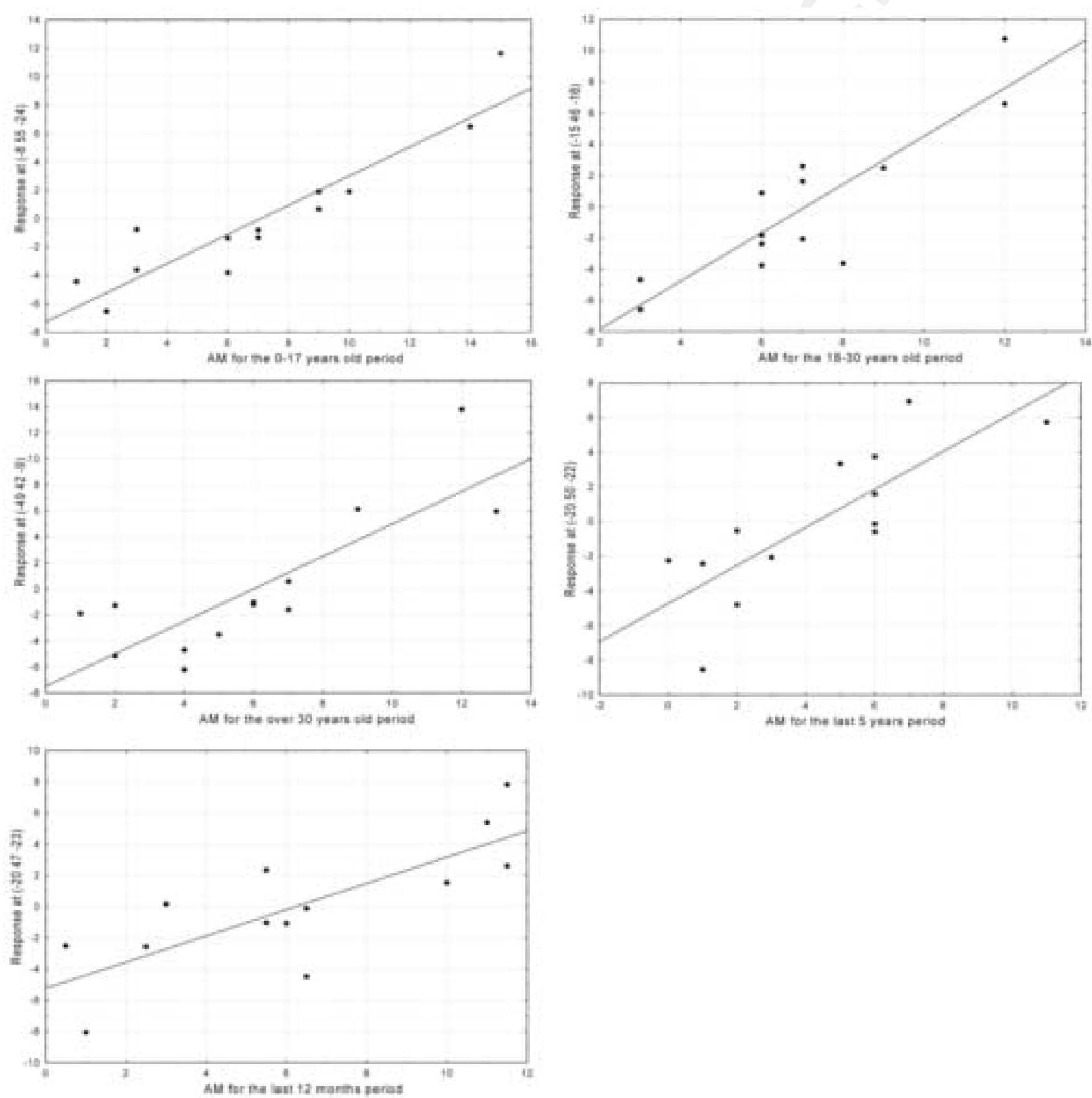


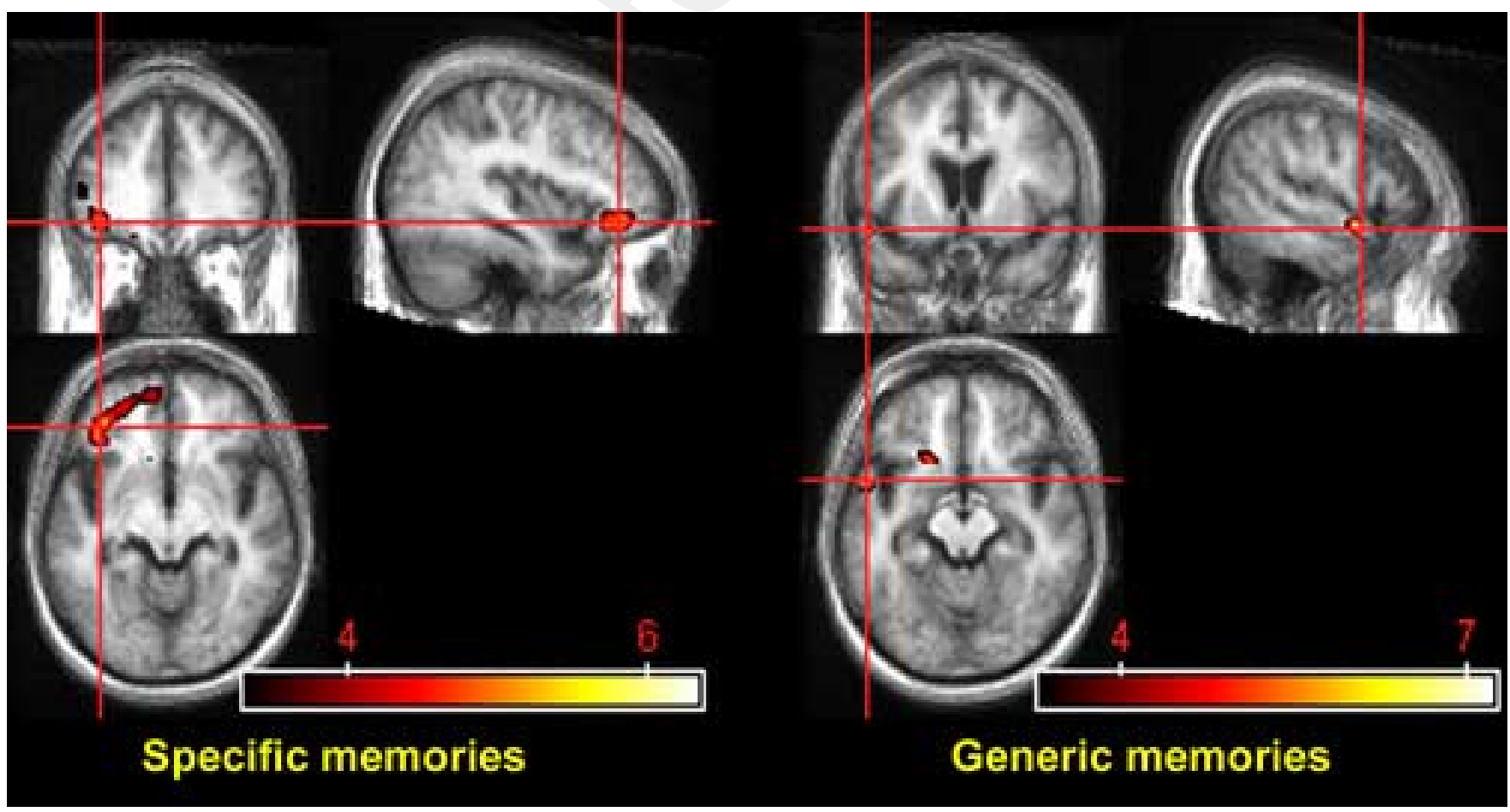

Page 49 of 